\title{
Delayed Recovery of Skeletal Muscle Mass following Hindlimb Immobilization in mTOR Heterozygous Mice
}

\author{
Susan M. Lang, Abid A. Kazi, Ly Hong-Brown, Charles H. Lang* \\ Department of Cellular and Molecular Physiology, Pennsylvania State University College of Medicine, Hershey, Pennsylvania, United States of America
}

\begin{abstract}
The present study addressed the hypothesis that reducing mTOR, as seen in mTOR heterozygous (+/-) mice, would exaggerate the changes in protein synthesis and degradation observed during hindlimb immobilization as well as impair normal muscle regrowth during the recovery period. Atrophy was produced by unilateral hindlimb immobilization and data compared to the contralateral gastrocnemius. In wild-type (WT) mice, the gradual loss of muscle mass plateaued by day 7. This response was associated with a reduction in basal protein synthesis and development of leucine resistance. Proteasome activity was consistently elevated, but atrogin-1 and MuRF1 mRNAs were only transiently increased returning to basal values by day 7. When assessed 7 days after immobilization, the decreased muscle mass and protein synthesis and increased proteasome activity did not differ between WT and $\mathrm{mTOR}^{+/-}$mice. Moreover, the muscle inflammatory cytokine response did not differ between groups. After 10 days of recovery, WT mice showed no decrement in muscle mass, and this accretion resulted from a sustained increase in protein synthesis and a normalization of proteasome activity. In contrast, mTOR ${ }^{+/-}$ mice failed to fully replete muscle mass at this time, a defect caused by the lack of a compensatory increase in protein synthesis. The delayed muscle regrowth of the previously immobilized muscle in the $\mathrm{mTOR}^{+-}$mice was associated with a decreased raptor-4EBP1 and increased raptor-Deptor binding. Slowed regrowth was also associated with a sustained inflammatory response (e.g., increased TNF $\alpha$ and CD45 mRNA) during the recovery period and a failure of IGF-I to increase as in WT mice. These data suggest mTOR is relatively more important in regulating the accretion of muscle mass during recovery than the loss of muscle during the atrophy phase, and that protein synthesis is more sensitive than degradation to the reduction in mTOR during muscle regrowth.
\end{abstract}

Citation: Lang SM, Kazi AA, Hong-Brown L, Lang CH (2012) Delayed Recovery of Skeletal Muscle Mass following Hindlimb Immobilization in mTOR Heterozygous Mice. PLoS ONE 7(6): e38910. doi:10.1371/journal.pone.0038910

Editor: Antonio Musaro, University of Rome La Sapienza, Italy

Received January 5, 2012; Accepted May 14, 2012; Published June 22, 2012

Copyright: (c) 2012 Lang et al. This is an open-access article distributed under the terms of the Creative Commons Attribution License, which permits unrestricted use, distribution, and reproduction in any medium, provided the original author and source are credited.

Funding: Funding from National Institutes of Health GM38032 supported the current research project (www.nih.gov). The funders had no role in study design, data collection and analysis, decision to publish, or preparation of the manuscript.

Competing Interests: The authors have declared that no competing interests exist.

*E-mail: clang@psu.edu

\section{Introduction}

The plasticity of skeletal muscle is evidenced by the hypertrophy seen with strength training and, conversely, the atrophy seen with disuse $[1,2]$. This atrophic response can be generalized when produced by extended periods of bed rest or localized when a single limb is immobilized [3-9]. This muscle wasting when sustained and severe can be a determinant of morbidity and mortality in chronic catabolic states, and results from an imbalance between rates of protein synthesis and breakdown. Previous studies have demonstrated that these metabolic processes change over time and are in part dependent on the etiology of the atrophic stimuli $[8,10-13]$. While the net catabolic response in muscle leads to the release of amino acids supporting select immune and metabolic responses, the sustained loss of muscle mass decreases strength and impairs ambulation [3,14,15]. Conversely, muscle reloading during the recovery phase results in the gradual accretion of mass and the ability to generate force $[3,16]$. As restoration of muscle mass is necessary to re-establish normal function, a greater understanding of mechanisms by which muscle is lost and regained is of clinical importance.

The mammalian target of rapamycin (mTOR) is the catalytic component of two multiprotein complexes, referred to as mTORC1 and mTORC2, which collectively regulate diverse cellular functions including protein balance [17]. The impairment in muscle protein synthesis produced by disuse is associated with both a reduction in the phosphorylation of downstream targets of mTORC1 such as eukaryotic initiation factor (eIF) 4E-binding protein-1 (4E-BP1) and ribosomal protein S6 kinase-1 (S6K1) [6,18-21] as well as S473-phosphorylation of Akt which is a recognized substrate for mTORC2 [18,20]. Additionally, inhibition of mTOR signaling enhances muscle protein degradation via activation of the ubiquitin proteasome system [22]. In general, mTOR senses and integrates inputs from nutrients, energy status and growth factors, as evidenced by the severe atrophy observed in mice with muscle-specific ablation of mTOR [23]. However, whether alterations in $\mathrm{mTOR}$ are causally related to the reduced muscle protein synthesis and increase in protein degradation produced by immobilization in adult animals is unclear. As mice with whole-body mTOR deletion (e.g., knockout [KO]) are embryonically lethal $[24,25]$ and mice with muscle-specific mTOR KO have a severe muscle pathology and die prematurely [23], we addressed this question using mice which are heterozygous $(+/-)$ for $\mathrm{mTOR}$ with an $\sim 50 \%$ reduction in total $\mathrm{mTOR}$ protein in skeletal muscle and other tissues [26]. Using these haploinsufficient mice and their wild-type (WT) littermates, we addressed the hypothesis that reduction of mTOR would exaggerate the changes in both protein synthesis and degradation 
Table 1. Comparison of unilateral and bilateral hindlimb immobilization ("casting") on body weight, food intake and muscle weight.

\begin{tabular}{|c|c|c|c|c|c|c|}
\hline & \multicolumn{2}{|c|}{ Control (naive) } & \multicolumn{2}{|c|}{ Unilateral casting } & \multicolumn{2}{|c|}{ Bilateral Casting } \\
\hline & Pre & Post & Pre & Post & Pre & Post \\
\hline Body weight, grams & $25.6 \pm 0.4$ & $26.1 \pm 0.4^{*}$ & $25.1 \pm 0.3$ & $25.7 \pm 0.6^{*}$ & $24.9 \pm 0.5$ & $24.7 \pm 0.6$ \\
\hline \multirow[t]{3}{*}{ Food Consumption, g/day } & $4.2 \pm 0.3$ & $4.3 \pm 0.3$ & $4.1 \pm 0.3$ & $4.2 \pm 0.4$ & $4.0 \pm 0.4$ & $3.6 \pm 0.5^{*}$ \\
\hline & \multicolumn{2}{|c|}{ Control (naive) } & \multicolumn{2}{|c|}{ Unilateral Casting } & \multicolumn{2}{|c|}{ Bilateral Casting } \\
\hline & Control & Control & Control & Casted & Control & Casted \\
\hline Muscle $\mathrm{Wt}, \mathrm{mg}$ & $111 \pm 5 a$ & $110 \pm 6 a$ & $109 \pm 5 a$ & $88 \pm 4 b$ & $85 \pm 4 b$ & $83 \pm 4 b$ \\
\hline
\end{tabular}

observed during a sustained period of hindlimb immobilization as well as impair normal muscle regrowth during the recovery period.

\section{Materials and Methods}

\section{Animal protocols}

All mice were housed under specific pathogen-free conditions and controlled environmental conditions (12:12 light:dark). Mice were provided Teklad Global 2019 (Harlan Teklad, Boston, MA) and water ad libitum. All breeding and experimental protocols were approved by the Institutional Animal Care and Use Committee of The Pennsylvania State University College of Medicine and adhered to the National Institutes of Health (NIH) guidelines for the use of experimental animals.

Experimental mice were either mTOR heterozygous $\left(\mathrm{mTOR}^{+/-}\right)$ or WT male littermates (12-16 wks, with a body weight of 26-28 g). The generation and phenotypic characterization of these mice has been previously described [26]. Briefly, Western blot analysis of gastrocnemius, heart and liver from $\mathrm{mTOR}^{+/-}$mice indicated a $\sim 50-60 \%$ reduction in the amount of total mTOR protein [26]. Whole-body mTOR heterozygous mice were used instead of a muscle-specific mTOR KO because various catabolic insults decreased mTOR phosphorylation by $\sim 50 \%$ under in vivo conditions [17], and there are no naturally occurring physiological or catabolic conditions characterized by the complete loss of mTOR protein in skeletal muscle. Moreover, mice with muscle-specific knockout of mTOR exhibit a serve wasting and permature death [23]. Therefore, while the use of whole-body mTOR h3eterozygous mice somewhat limits data interpretation, we believe this animal model represents a more physiological experimental paradigm.

Mice were anesthetized with isoflurane $\left(2-3 \%\right.$ in $\mathrm{O}_{2}+1.5 \%$ maintenance) for hindlimb immobilization [12]. Briefly, hair on the left lower hindlimb was removed with clippers, the skin swabbed with $70 \%$ alcohol, and the hindlimb wrapped with a single layer of surgical tape. A small amount of generic superglue was applied to the tape and a $1.5 \mathrm{ml}$ plastic microfuge tube without the lid was placed over the leg, maintaining the foot in a plantar-flexed position to induce maximal atrophy of the gastrocnemius. The bottom of the tube was also removed so as to prevent condensation inside the tube. The weight of the tube was $\sim 500 \mathrm{mg}(\sim 2 \%$ of body weight $)$ and did not appear to limit animal mobility. The contralateral leg was not immobilized and served as the internal control. The contralateral leg does not undergo hypertrophy (see Table 1), and the validity of this unilateral hindlimb immobilization has been previously reported for other animal models [27,28]. Each mouse received $1 \mathrm{ml}$ of warmed $\left(37^{\circ} \mathrm{C}\right)$ sterile $0.9 \%$ saline for resuscitation. After casting, mice were housed individually for various periods of time with food and water ad libitum. Food was placed in both the overhead bin and within the cage to permit easy access. A second study was performed in which the hindlimb was immobilized for 7 days and then the cast removed so muscle recovery could be assessed at various time points. In some mice, body composition was monitored non-invasively in conscious animals using a ${ }^{1} \mathrm{H}-\mathrm{NMR}$ analyzer (Bruker LF90 Proton-NMR Minispec: Bruker Optics, Woodlands, TX) for rapid measurement of total body lean and fat mass [26]. In a separate study, WT mice were used at either after: a) 5 days of immobilization or b) after 7 days of immobilization and 10 days of recovery. Mice in this study were fasted for $4 \mathrm{~h}$ and then administered an oral gavage of either leucine $(1.35 \mathrm{~g} / \mathrm{kg}$ body wt) or an equal volume of saline, and skeletal muscle was excised 30 min thereafter. The dose and timing of leucine administration were based on prior studies demonstrating maximal stimulation of muscle protein synthesis as well as mTOR signaling [26].

\section{In vivo protein synthesis}

The in vivo rate of protein synthesis in the gastrocnemius (hereafter referred to as muscle) was determined in the control and immobilized limb at various time points after immobilization ("casting"). Protein synthesis was determined using the floodingdose technique, as described [8,12,26,29]. Mice were injected intraperitoneal with $\left[{ }^{3} \mathrm{H}\right]$-L-phenylalanine $(150 \mathrm{mM}, 30 \mu \mathrm{Ci} / \mathrm{ml}$; $1 \mathrm{ml} / 100 \mathrm{~g}$ body $\mathrm{wt}$ ), and blood was collected $15 \mathrm{~min}$ later from the abdominal aorta. The plasma phenylalanine concentration and radioactivity was measured by HPLC analysis of supernatant from TCA extracts of plasma. Thereafter, muscles were rapidly excised. A portion of muscle was freeze-clamped, stored at $-70^{\circ} \mathrm{C}$, and processed as previously described $[8,29,30]$. The rate of protein synthesis was calculated by dividing the amount of radioactivity incorporated into protein by the plasma phenylalanine-specific radioactivity. The advantages and disadvantages of this method have been reviewed [31]. In addition, samples of fresh muscle were homogenized for Western blot and analysis of selected proteins and another piece of tissue used for qRT-PCR, as described below. 


\section{Western blotting and immunoprecipitation}

Fresh skeletal muscle was homogenized (Kinematic Polytron; Brinkmann, Westbury, NY) in ice-cold homogenization buffer consisting of (in mmol/L): 20 HEPES ( $\mathrm{pH} 7.4$ ), 2 EGTA, 50 sodium fluoride, 100 potassium chloride, 0.2 EDTA, $50 \beta$ glycerophosphate, 1 DTT, 0.1 phenylmethane-sulphonylfluoride, 1 benzamidine, and 0.5 sodium vanadate. The protein concentration was quantified using the Bio-Rad protein assay kit (BioRad, Hercules, CA) and equal amounts of total protein per sample were subjected to standard SDS-PAGE. The blots were incubated with primary antibodies to total and phosphorylated proteins (Cell Signaling, Beverly, MA, unless otherwise noted), including total and phosphorylated 4E-BP1 (Thr 37/46; Bethyl Laboratories, Montgomery, TX), total and phosphorylated S6 (S240/244), total and phosphorylated Akt (S473), total and phosphorylated PRAS40 (proline-rich Akt substrate 40; Biosource, Camarillo, CA), total $\mathrm{S} 6 \mathrm{~K} 1$, total raptor (regulatory-associated protein of TOR), and total Deptor (DEP-domain partner of mTOR; Millipore, Billerica, MA). Tubulin and eIF4E were, on occasion, used as loading controls. Blots were developed with enhanced chemiluminescence Western blotting reagents (Supersignal Pico, Pierce Chemical, Rockford, IL). Dried blots were exposed to x-ray film to achieve a signal within the linear range and film was then scanned (Microtek ScanMaker IV; Cerritos, CA) and quantified using Scion Image 3b software (Scion Corporation, Frederick, MD). Additionally, eIF4E was immunoprecipitated from aliquots of supernatants using an anti-eIF4E monoclonal antibody (Drs. Jefferson and Kimball; Hershey, PA). Antibody-antigen complexes were collected using magnetic beads subjected to SDS-PAGE. The 4E-BP1•eIF4E and eIF4G•IF4E complexes were then quantified, as described above.

To maintain potential protein-protein interactions within mTORC1, fresh muscle was homogenized in CHAPS buffer $(\mathrm{pH} 7.5)$ composed of the following (in $\mathrm{mM}$ ): 40 HEPES, $120 \mathrm{NaCl}, 1$ EDTA, 10 pyrophsophate, $10 \beta$-glycerophosphate, $50 \mathrm{NaF}, 1.5$ sodium vanadate, $0.3 \%$ CHAPS, and one protease inhibitor cocktail tablet. The homgenate was clarified by centrifugation, and an aliquot of the supernatant was combined with anti-raptor antibody and immune complexes were isolated with goat anti-rabbit BioMag IgG (PerSeptive Diagnostics, Boston, MA) beads. The beads were collected, washed with CHAPS buffer, precipitated by centrifugation, and subjected to SDSPAGE and quantitated as described above.

\section{RNA extraction and real-time quantitative $P C R$}

Total RNA was extracted using Tri-reagent (Molecular Research Center, Inc., Cincinnati, OH) and RNeasy mini kit (Qiagen, Valencia, CA) following manufacturers' protocols. Skeletal muscle was homogenized in tri-reagent followed by chloroform extraction according to the manufacturer's instruction. An equal volume of $70 \%$ ethanol was added to the aqueous phase and the mixture was loaded on a Qiagen mini spin column. The Qiagen mini kit protocol was followed from this step onwards including the on-column DNase I treatment to remove residual DNA contamination. RNA was eluted from the column with RNase-free water and an aliquot was used for quantitation (NanoDrop 2000, Thermo Fisher Scientific, Waltham, MA). Quality of the RNA was analyzed on a $1 \%$ agarose gel. Total RNA $(1 \mu \mathrm{g})$ was reversed transcribed using superscript III reverse transcriptase (Invitrogen, Carlsbad, CA) following manufacturer's instruction. Real-time quantitative PCR was performed using $25 \mathrm{ng}$ of cDNA in a StepOnePlus system using TaqMan gene expression assays (Applied Biosystems, Foster City, CA) for: Atrogin 1 (F-box protein 32; Mm00499523_ml), muscle RINGfinger 1 (MuRF1; Mm01185221_m1), interleukin (IL)-6
(Mm00446190_ml), tumor necrosis factor (TNF)- $\alpha$ (Mm00443258_m1), CD45 (Mm01293575_ml), insulin-like growth factor-I (IGF-I; Mm00439560_m; all IGF-I transcripts) and glyceraldehyde-3-phosphate dehydrogenase (GAPDH; Mm99999915_gl). The comparative quantitation method $2^{-\Delta \Delta \mathrm{Ct}}$ was used in presenting gene expression of target genes in reference to the endogenous control [32].

\section{Proteasome activity assay}

Gastrocnemius was homogenized in 4 volumes of ice-cold $50 \mathrm{mM}$ Tris (pH 7.5) containing $1 \mathrm{mM}$ EDTA, $150 \mathrm{mM} \mathrm{NaCl}$, $5 \mathrm{mM} \mathrm{MgCl}_{2}, 50 \mu \mathrm{M} \mathrm{ATP}$, and $0.5 \mathrm{mM}$ DTT followed by centrifugation at $12,000 \times \mathrm{g}$ for $30 \mathrm{~min}$ at $4^{\circ} \mathrm{C}$. The proteasome enzymatic activity was measured by using a proteasome $20 \mathrm{~S}$ assay kit (Enzo Life Sciences, Farmingdale, NY) following the manufacturer's instructions. Briefly, determination of the chymotrypsinlike protease activity of the $20 \mathrm{~S}$ proteasome in samples was initiated by addition of a fluorogenic peptidyl substrate succinylLeu-Leu-Val-Tyr-7-amido-4-methylcoumarin (Suc-LLVY-AMC) to wells of a 96-well plate containing $50 \mu \mathrm{g}$ of homogenized muscle sample. This substrate was cleaved by the proteasome activity and the subsequently released free AMC was then detected by a fluorometer (SpectraMax M5; Molecular Devices Corporation, Sunnyvale, CA) using an excitation wavelength of $360 \mathrm{~nm}$ and emission wavelength of $460 \mathrm{~nm}$. The fluorescence signal was monitored before and at 10 -min for 2 hours at $37^{\circ} \mathrm{C}$. The change in fluorescence signal was normalized to the amount of protein used in the assay and all assays were in the linear range. Each sample/substrate combination was measured both in the presence and in the absence of MG132, a highly specific $20 \mathrm{~S}$ proteasome inhibitor (Boston Biochem, Cambridge, MA) to account for any non-proteasomal degradation of the substrate. These fluorescence units were then subtracted from each measurement. Results are expressed as $\mu \mathrm{mol} / \mathrm{mg}$ protein $/ \mathrm{min}$ or presented as percent of time-matched control value.

\section{Plasma IGF-I and insulin concentrations}

The plasma concentrations of total IGF-I and insulin were measured using commercial ELISA kits (Diagnostic Systems Laboratory, Webster, TX and Linco Research, St. Louis, MO, respectively).

\section{Statistics}

Data for each condition are summarized as means \pm standard error of the mean (SEM) where the number of mice per treatment is indicated in the legend to the figure or table. Statistical evaluation of the data was performed using ANOVA with posthoc Student-Neuman-Keuls test when the interaction was significant. To compare changes in the immobilized muscle to the non-immobilized control muscle in the same mouse, a 2-tailed paired $t$-test was performed. Differences between groups were considered significant at $P<0.05$. GraphPad Prism version 5.0 (GraphPad software, La Jolla, CA) was used for statistical analysis.

\section{Results}

\section{Model characterization}

An initial study was performed to determine whether unilateral or bilateral hindlimb immobilization was the preferable model for investigating disuse atrophy in mice. Naive control mice gained approximately $0.5 \mathrm{~g}$ over the 5 day observation period. Body weight and food consumption of mice where only one hindlimb was immobilized was not different from that of naive control mice 
A

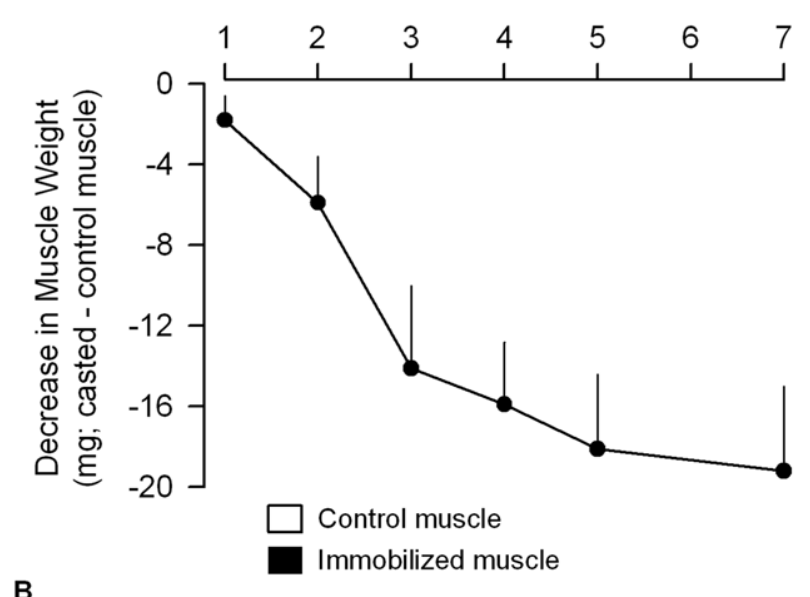

B

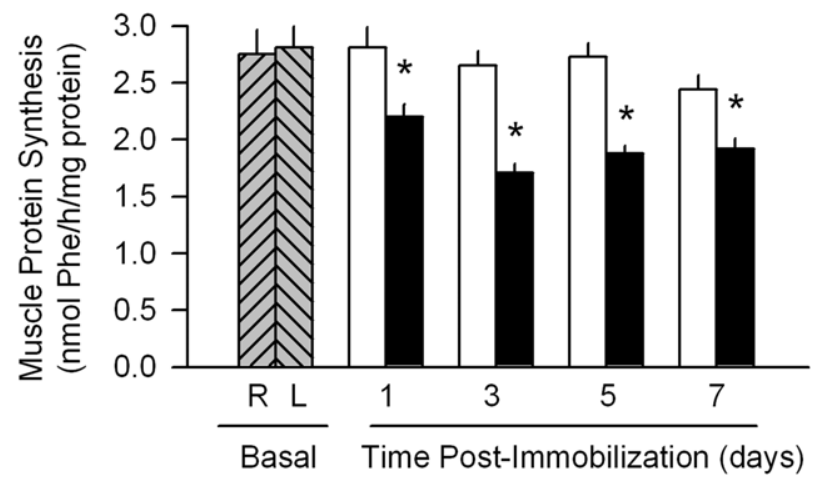

Figure 1. Temporal progression of changes in muscle mass and protein synthesis after unilateral hindlimb immobilization. (A) Decrement in mass of gastrocnemius at various times after immobilization, compared to contralateral non-casted muscle from the same mouse. All values from day $2-7$ are statistically $(P<0.05)$ decreased. Values are means \pm SEM; $n=7-9$ per time point. (B) In vivo-determined protein synthesis of gastrocnemius from immobilized and control (e.g., non-immobilized) muscle at various times after casting. First two crosshatched bars, represent protein synthesis of the right (R) and left (L) gastrocnemius from naive control mice. ${ }^{*} P<0.05$, compared to contralateral non-casted control muscle of the same mouse. Values are means \pm SEM; 7-9 mice per group.

doi:10.1371/journal.pone.0038910.g001

(Table 1). In contrast, mice which had both hindlimbs immobilized failed to gain weight and consumed $\sim 10 \%$ less food than control animals. The reduced food intake by bilaterally casted mice was not due to their inability to obtain food because food was provided within the animal's cage. The same magnitude of muscle mass loss was detected in the immobilized muscle from animals in which either one or two hindlimbs were casted. The weight of the uncasted muscle in the unilateral casted group did not differ from that of muscle of naive control mice. Finally, the in vivo-determined rate of protein synthesis in control muscle from unilateral casted mice did not differ from the synthetic rate of muscles from naive control mice (Figure 1B). Collectively, these data suggest bilateral immobilization is more stressful to mice than immobilization of a single hindlimb and the gastrocnemius from the uncasted limb does not undergo either a compensatory hypertrophy or a change in protein synthesis. Hence, all subsequent studies were performed using unilateral immobilization.

Figure 1A illustrates the progressive decrease in weight of the gastrocnemius from the immobilized limb over the 7-day course of

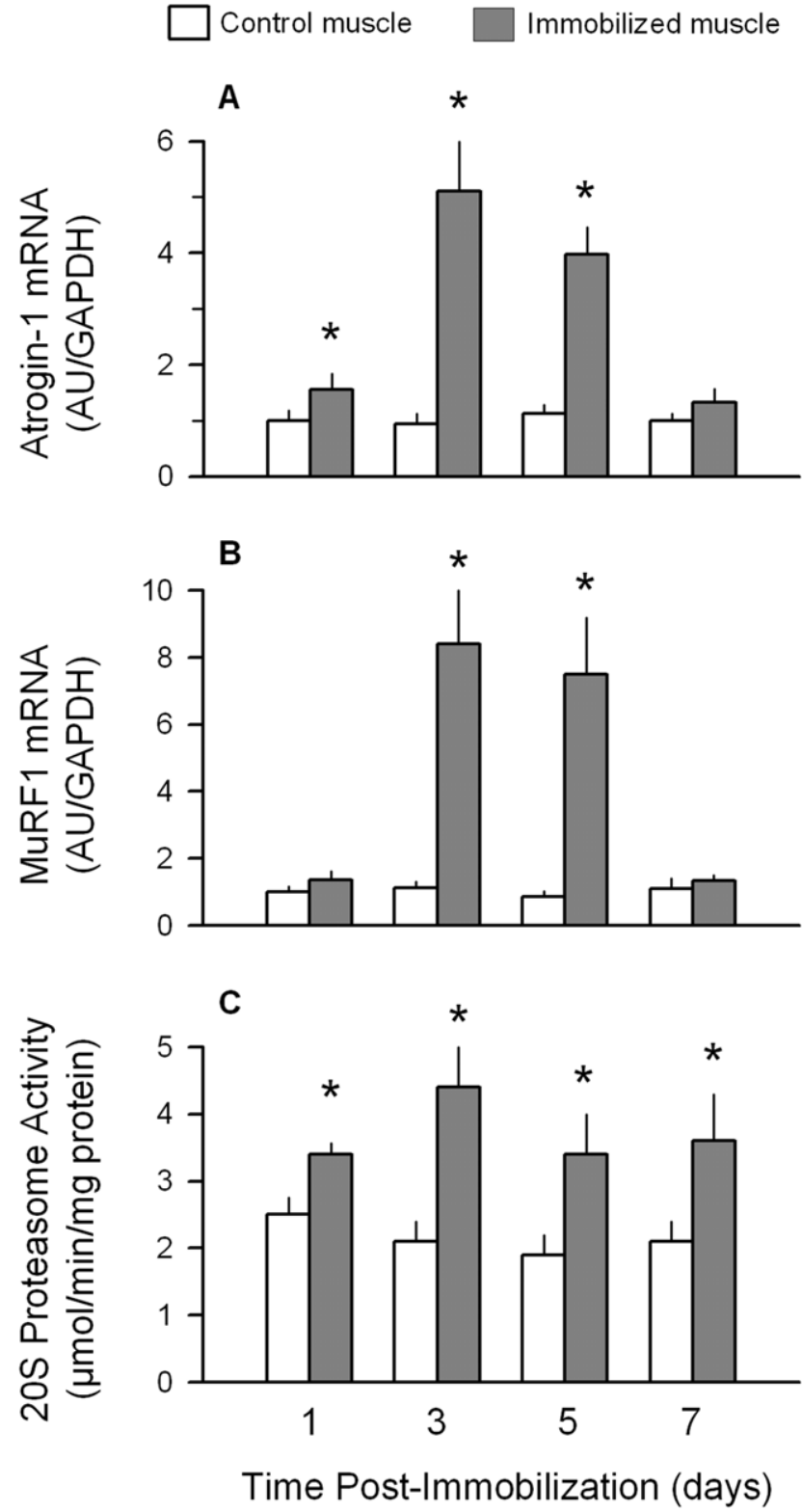

Figure 2. Temporal progression of changes in atrogin-1 and MuRF1 mRNA content and proteasome activity after unilateral hindlimb immobilization. (A) Quantitation of mRNA content of gastrocnemius for atrogin-1 at various times after unilateral hindlimb immobilization, compared to contralateral non-casted control muscle. (B) Quantitation of mRNA for MuRF1 in gastrocnemius at various times after immobilization. All mRNA data were normalized to GAPDH and the WT control value was set at 1.0 arbitrary units (AU/GAPDH). (C) $20 \mathrm{~S}$ proteasome activity determined in immobilized and control muscle. ${ }^{*} P<0.05$, compared to contralateral non-casted control muscle of the same mouse. Values are means \pm SEM; 7-9 mice per group. doi:10.1371/journal.pone.0038910.g002

study. This atrophic response appeared to plateau between 57 days after casting. In vivo-determined protein synthesis was decreased as early at $24 \mathrm{~h}$ after immobilization and this reduction was sustained for at least 7 days (Figure 1B). Protein synthesis was reduced $25-30 \%$ in the immobilized muscle, compared to the contralateral muscle, during this time period.

Temporal changes in the other side of the protein balance equation, that is protein degradation, were also assessed. The 
A

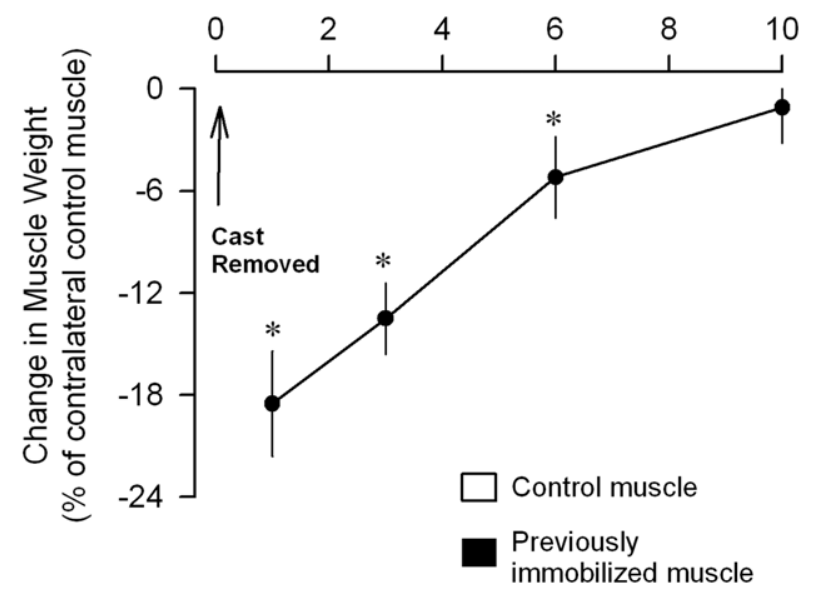

B

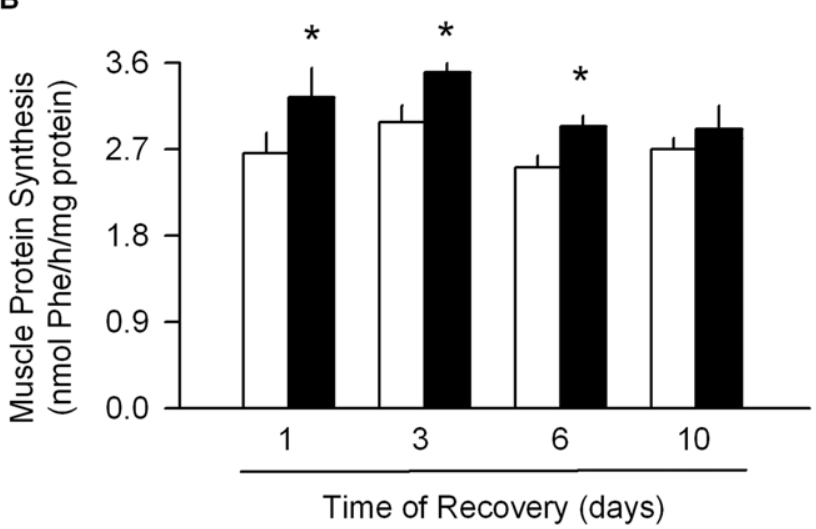

Figure 3. Temporal progression of changes in muscle mass and protein synthesis at various times after cast removal and muscle reloading.(A) Hindlimb immobilization was produced for 7 days, the cast removed, and the change in gastrocnemius mass determined at various times during the recovery period. Data are expressed as a change in muscle weight of the immobilized limb compared to that of the contralateral limb in the same mouse. (B) In vivo-determined protein synthesis of gastrocnemius from previously immobilized (7 days) and control muscle at various times after cast removal. For both graphs, ${ }^{*} \mathrm{P}<0.05$, compared to contralateral noncasted control muscle from the same mouse. Values are means \pm SEM; 7-9 mice per group.During recovery, there was no statistically significant difference between the previously immobilized muscle and the non-casted control muscle at any time point for either atrogin-1 or MuRF1 mRNA content (Figure 4A and 4B). In contrast, the proteasome activity in the previously immobilized muscle was increased $70 \%$ on day 1 of recovery, but was not different from control values at all other recovery time points.

doi:10.1371/journal.pone.0038910.g003

muscle-specific E3 ligases atrogin-1 and MuRF1, collectively referred to as atrogenes, are increased in disuse atrophy as well as a number of diverse catabolic conditions [8,10,18,26,33-36]. The mRNA content for atrogin- 1 was slightly, albeit statistically, increased $(60 \%) 1$ day after immobilization (Figure 2A), with the increase peaking between days $3-5$, before returning to control values by day 7. The immobilization-induced increase in MuRF1 was comparable to that seen for atrogin-1, except levels were not increased at the 1 day time point (Figure 2B). In contrast to the relatively transient changes in the mRNA content for these two E3 ligases, proteasome activity was consistently increased (approximately 75\%) from day 1 through day 7 of immobilization (Figure 2C).

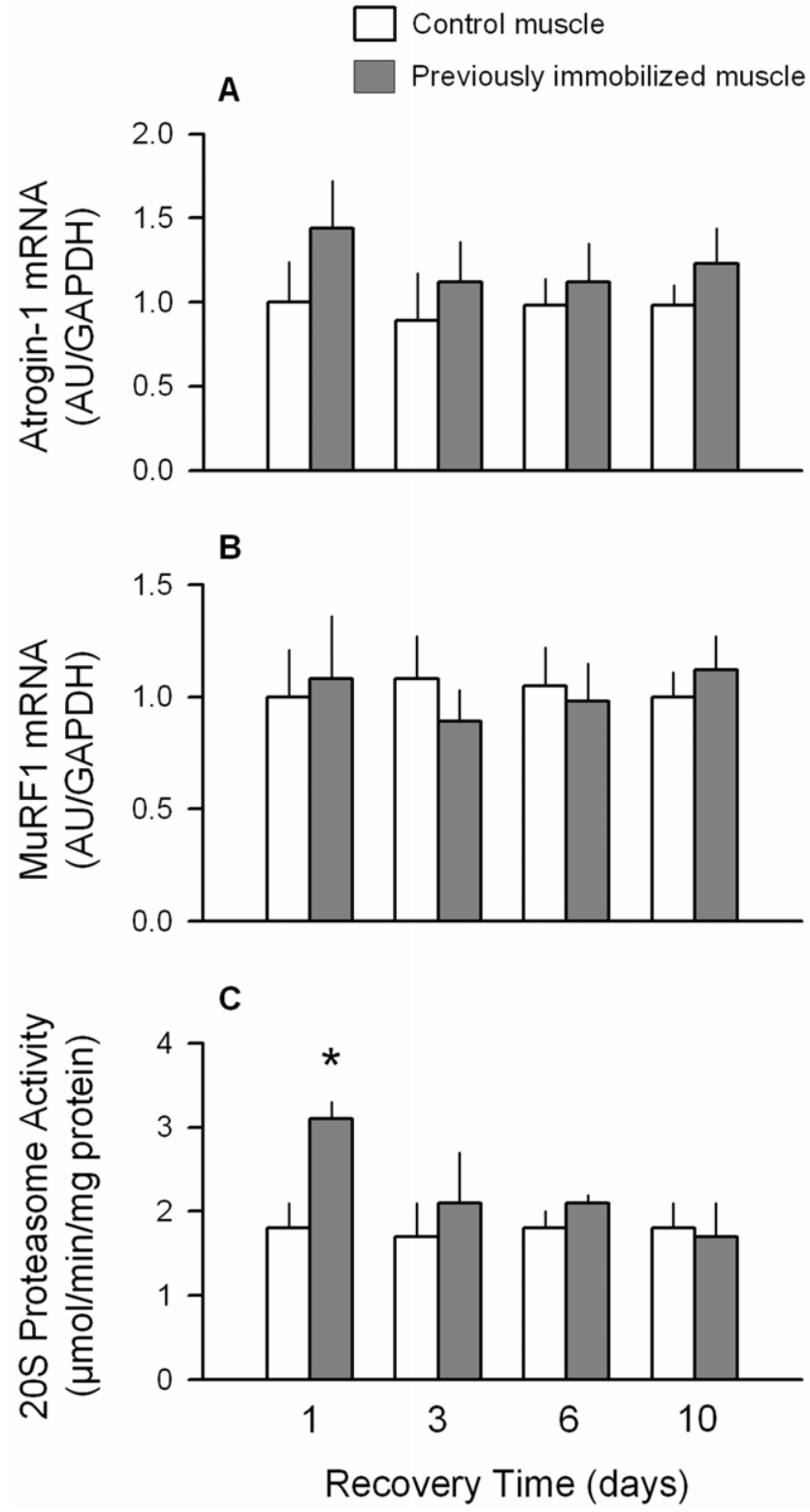

Figure 4. Temporal progression of changes in atrogin-1 and MuRF1 mRNA content and proteasome activity after cast removal and muscle reloading. (A-B) Quantitation of mRNA content of gastrocnemius for atrogin-1 and MuRF1, respectively, at various times during the recovery period. Hindlimb immobilization was produced for 7 days, the cast removed, and muscles excised at various time points thereafter. All data were normalized to GAPDH and the WT control value was set at 1.0 arbitrary units (AU/GAPDH). (C) $20 \mathrm{~S}$ proteasome activity determined in immobilized and control muscle after cast removal. ${ }^{*} P<0.05$, compared to contralateral non-casted control muscle for the same mouse. Values are means \pm SEM; 7-9 mice per group.

doi:10.1371/journal.pone.0038910.g004

We also examined the temporal progression for the recovery of muscle mass following cast removal and muscle reloading. The mass of the previously immobilized muscle gradually increased from day 1 through day 10 of the recovery period (Figure 3A). The weight of the previously immobilized muscle was reduced, compared to the contralateral non-casted muscle, from days 16 . However, by day 10 of recovery, there was no difference in the weight of the two muscles. This recovery pattern was accompanied 


\section{Day 5 Immobilization}

\section{Control muscle}
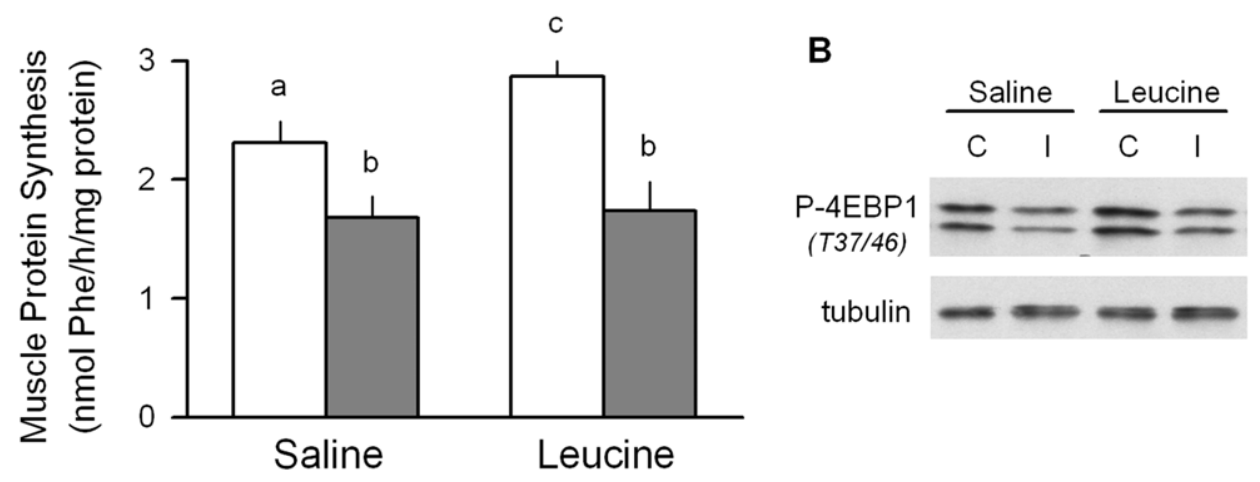

\section{Day 10 Recovery}

C Control muscle

Previously immobilized muscle
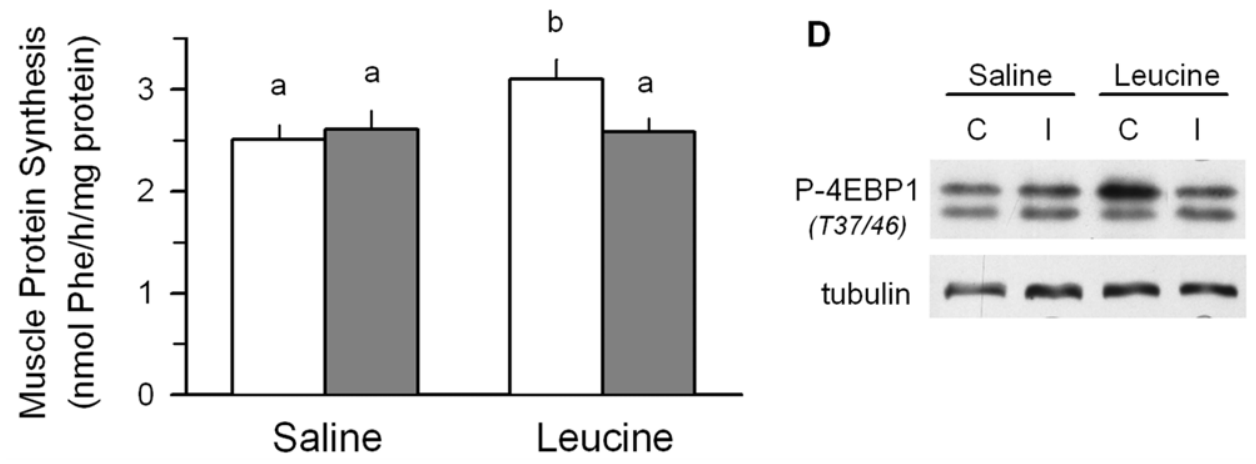

Figure 5. Immobilization-induced muscle leucine resistance. Unilateral hindlimb immobilization was produced for either 5 days (A-B) or for 7 days followed by a 10 day recovery period (C-D). (A and C) Protein synthesis was determined in both the immobilized and contralateral control muscle from $4 \mathrm{~h}$ fasted WT mice which were orally gavaged with either leucine or an equal volume of saline. Values with different superscript letters $(a, b)$ are statistically significant $(P<0.05)$. Values are means \pm SEM; 7-9 mice per group. (B and $D)$ Representative Western blot for Thr37/46phosphorylated 4E-BP1 (top band $=\gamma$-isoform; bottom band $=\beta$ isoform) in muscle from mice similarly treated. Blots are representative of $\mathrm{n}=5-6$ per group. Tubulin was used a loading control and demonstrated equal loading. doi:10.1371/journal.pone.0038910.g005

by an increased protein synthesis from days 1-6 which averaged $\sim 20 \%$ above control values (Figure 3B). However, protein synthesis did not differ between the previously immobilized and the non-casted control muscle at the 10-day time point.

During recovery, there was no statistically significant difference between the previously immobilized muscle and the non-casted control muscle at any time point for either atrogin-1 or MuRF1 mRNA content (Figure 4A and 4B). In contrast, the proteasome activity in the previously immobilized muscle was increased $70 \%$ on day 1 of recovery, but was not different from control values at all other recovery time points.

\section{Immobilization produces muscle leucine resistance}

Next, unilateral hindlimb immobilization was produced for 5 days and then animals were orally gavaged with a maximally- stimulating dose of the branch-chain amino acid leucine or saline as a control. The 5-day time point was selected based on the previously presented data indicating atrophic muscle was characterized by a decrease in protein synthesis and an increase in proteasome activity and atrogene expression. Mice gavaged with saline showed the typical decrease in muscle protein synthesis in the immobilized muscle (Figure 5A). In mice orally administered leucine, the rate of protein synthesis in the control (i.e., nonimmobilized) muscle was greater than that seen in the control muscle from the saline-treated group. However, leucine failed to increase muscle protein synthesis in the immobilized muscle. Immobilization- and leucine-induced changes in the extent of $4 \mathrm{E}$ BP1 Thr37/46-phosphorylation were detected (Figure 5B) and were comparable to those seen for protein synthesis. The ability of leucine to stimulate protein synthesis and 4E-BP1 phosphorylation 


\section{Immobilization Phase}

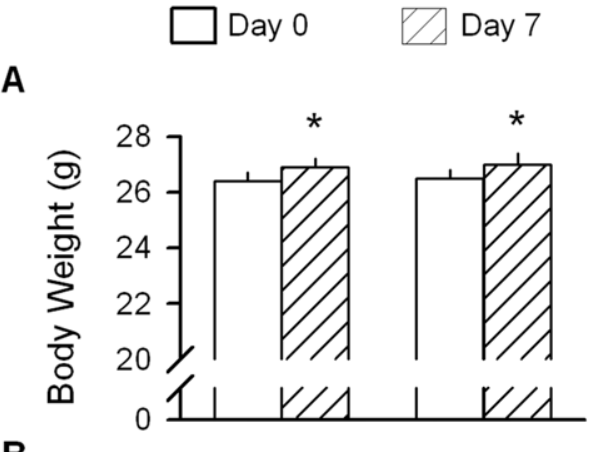

B

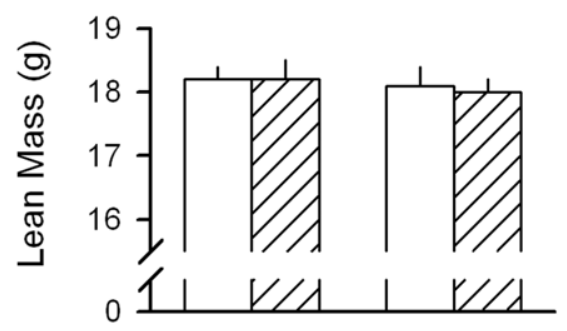

C

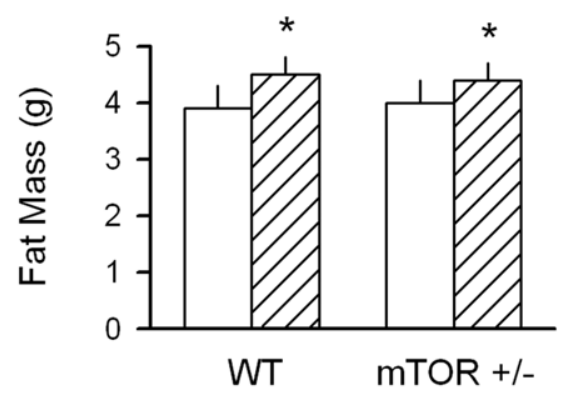

Recovery Phase

D
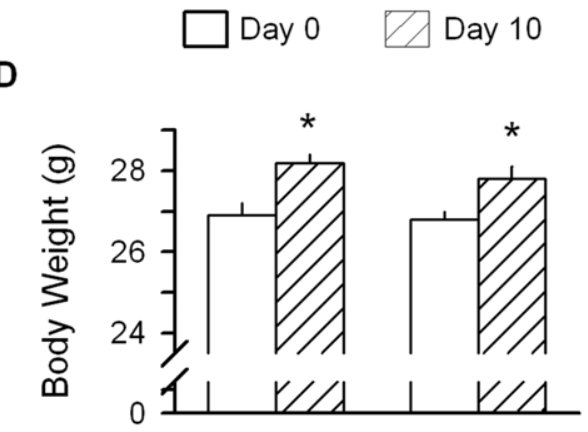

E

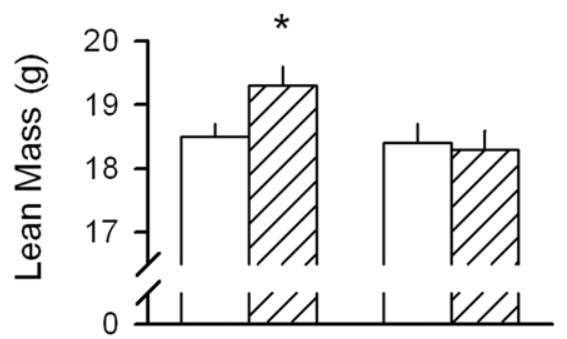

$\mathbf{F}$

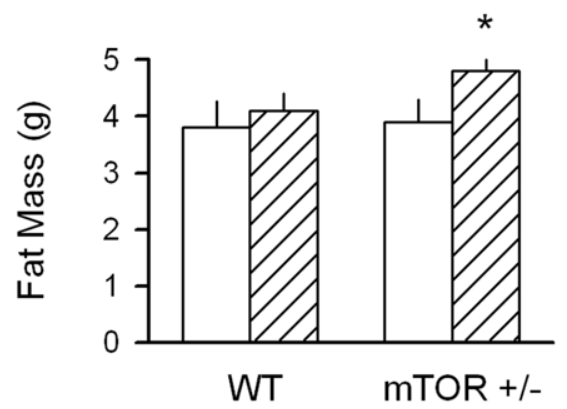

Figure 6. Effect of immobilization and reloading in wild-type (WT) and $\mathbf{m T O R}^{+/-}$mice on body composition. (A-C) Quantitation of body composition determined in WT and $\mathrm{mTOR}^{+/-}$mice immediately prior to and 7 days after unilateral hindlimb immobilization. (D-F) Quantitation of body composition determined in WT and $\mathrm{mTOR}^{+/-}$mice on day 10 of muscle reloading which was preceded by 7 days of immobilization (e.g., day 0). For all bar graphs, values are means \pm SEM; 7-9 mice per group. ${ }^{*} P<0.05$, compared to respective time-matched value from WT mice. doi:10.1371/journal.pone.0038910.g006

was still blunted in the previously immobilized muscle which was permitted to recover for 10 days (Figure 5C and 5D, respectively). As muscle was sampled at $30 \mathrm{~min}$ after leucine administration, leucine-induced change in atrogene mRNA or proteasome activity were detected (data not shown).

\section{Impact of hindlimb immobilization and muscle reloading on body composition of WT and mTOR+/- mice}

There was no difference in the body weight, lean mass or fat mass of $\mathrm{WT}$ and $\mathrm{mTOR}^{+/-}$mice at the start of the experiment (i.e., basal condition) (Figure 6A, 6B and 6C, respectively). After 7 days of unilateral hindlimb immobilization, the increase in body weight was comparable for both $\mathrm{WT}$ and $\mathrm{mTOR}^{+/-}$mice. The elevated body weight in both groups was primarily, if not exclusively, due to an increased fat mass.

Body weight, lean mass and fat mass did not differ between WT and $\mathrm{mTOR}^{+/-}$mice at the time of cast removal (Figure 6D, 6E and $6 \mathrm{~F}$, respectively). After a 10 -day recovery period, WT mice exhibited an increased body weight which could be solely accounted for by an increased lean mass, with no significant increased in fat mass. In contrast, while $\mathrm{mTOR}^{+/-}$mice showed a comparable increase in body weight during the recovery period, this change was due to an increase in fat as opposed to lean mass.

Role of mTOR in mediating protein balance during immobilization and recovery. Hindlimb immobilization in WT mice produced the expected decrease in muscle mass which was accompanied by a decreased protein synthesis (Figure 7A and 7B, respectively). mTORC1 and mTORC2 signaling was assessed by determining the phosphorylation of 4E-BP1 (T37/46) and Akt (S473), respectively [37]. In WT mice, immobilization decreased the phosphorylation of both 4E-BPl and Akt, without significantly reducing the total amount of either protein (Figure $7 \mathrm{C}$ ). Conversely, proteasome activity of immobilized muscle from WT mice was increased 2-fold, compared to the control muscle from the same animals (Figure 7D). Finally, these immobilizationinduced changes in protein metabolism did not differ between WT and $\mathrm{mTOR}^{+1-}$ mice.

To determine whether the temporal progression of muscle recovery after immobilization differed between $\mathrm{WT}$ and $\mathrm{mTOR}^{+/-}$ mice, a separate experiment was performed in which both groups of mice were subjected to hindlimb immobilization for 7 days, the cast removed and the muscles examined at various times after reloading. Figure 8 illustrates the weight of previously immobilized muscle 


\section{Immobilization Phase}

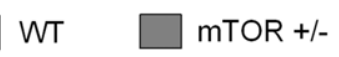

A

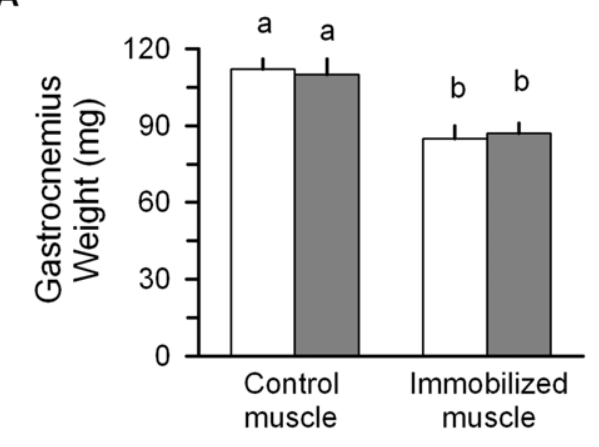

C

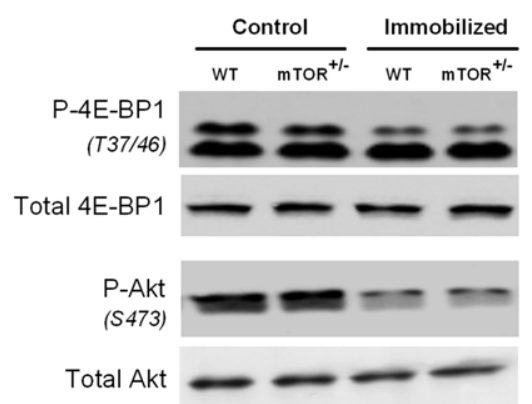

B

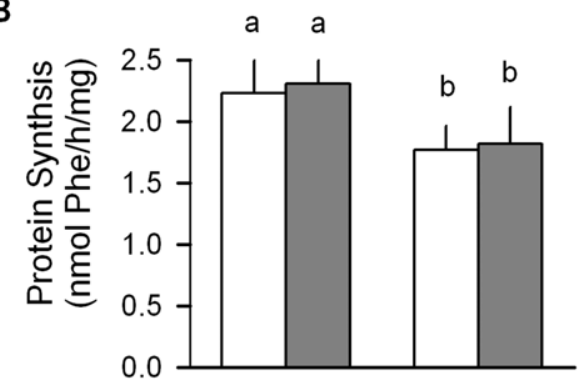

D

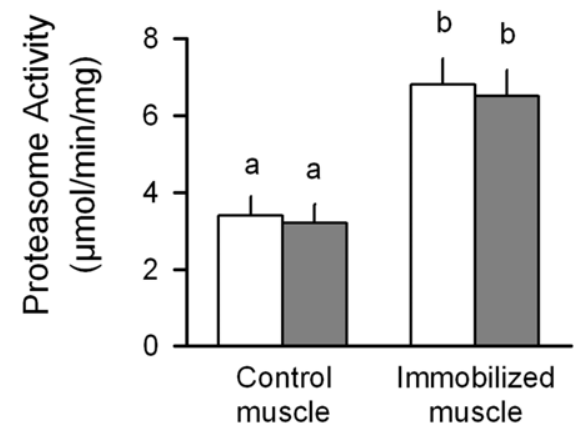

Figure 7. Protein metabolic effects of immobilization in wild-type (WT) and $\mathbf{~ T T O R}^{+/-}$mice. All parameters were determined in control and immobilized muscle from WT and $\mathrm{mTOR}^{+/-}$mice 7 days after unilateral hindlimb casting. Values with different superscript letters (a,b) are statistically significant $(P<0.05)$. For all bar graphs $(A, B$ and $D)$, values are means $\pm S E M ; 7-9$ mice per group. (C) Western blot data are representative of $n=5$ per group.

doi:10.1371/journal.pone.0038910.g007

from WT mice had recovered to that of the control muscle after 10 days of reloading. In contrast, the weight of previously immobilized muscle from $\mathrm{mTOR}^{+/-}$mice was statistically lower

Time of Recovery (days)

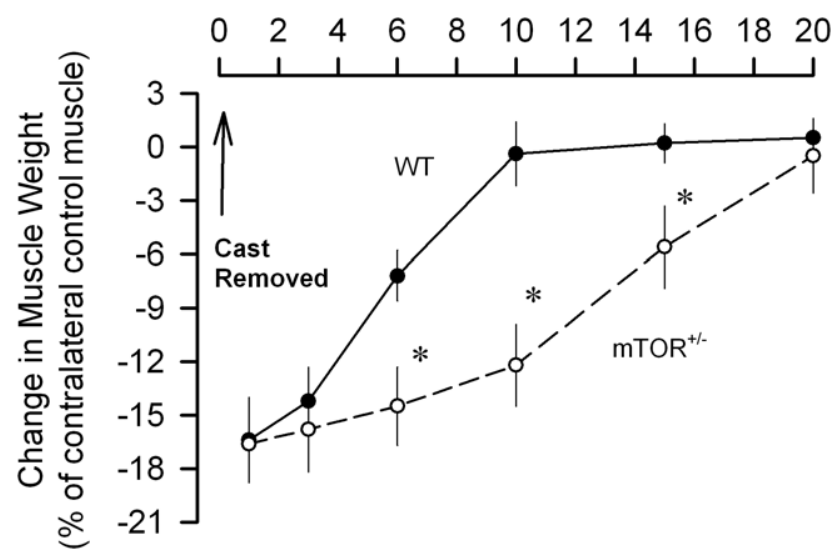

Figure 8. Temporal progression of regrowth in previously immobilized muscle in wild-type (WT) and $\mathrm{mTOR}^{+/-}$mice. Mice had one hindlimb casted for a period of 7 days, the cast removed, and muscle weight assessed at various time points during recovery. Values are means \pm SEM; 5-6 mice per group. ${ }^{*} P<0.05$, compared to timematched value from WT mice.

doi:10.1371/journal.pone.0038910.g008 at days 6, 10 and 15 days of recovery, with muscle weight not achieving control values until approximately day 20 following cast removal. Because the difference between $\mathrm{WT}$ and $\mathrm{mTOR}^{+/-}$mice was maximal after 10 days of reloading, additional studies characterizing skeletal muscle protein balance were performed at this time point.

At the end of a 10-day recovery period, the weight of the previously immobilized gastrocnemius from WT mice was not different from the non-casted contralateral muscle (Figure 9A). The rate of protein synthesis (Figure 9B) as well as the phosphorylation of 4E-BP1, S6 (e.g., substrate for S6K1), AKT and PRAS40 (Figure 9C) also did not differ between the two muscles from WT mice at this time. Finally, there was no difference in proteasome activity between control and previously immobilized muscle from WT mice (Figure 9F). In contrast, in $\mathrm{mTOR}^{+/-}$mice the weight of the previously immobilized muscle remained lower than that of the contralateral control muscle at the 10-day time point. This failure to fully recover muscle mass in the mTOR heterozygous mice at this time was associated with a lower rate of protein synthesis, but was independent of a change in proteasome activity. Although no difference was detected between the control and previously immobilized muscle of $\mathrm{mTOR}^{+/-}$mice for phosphorylated S6, Akt or PRAS40, the phosphorylation of $4 \mathrm{E}-\mathrm{BP} 1$ remained reduced in previously casted muscle, compared to control values from the contralateral muscle.

When the same amount of eIF4E was immunoprecipitated in all groups, the amount of 4E-BP1 bound to eIF4E (e.g., inactive capbinding complex) was increased in previously immobilized muscle 


\section{Recovery Phase}

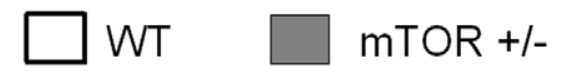

A

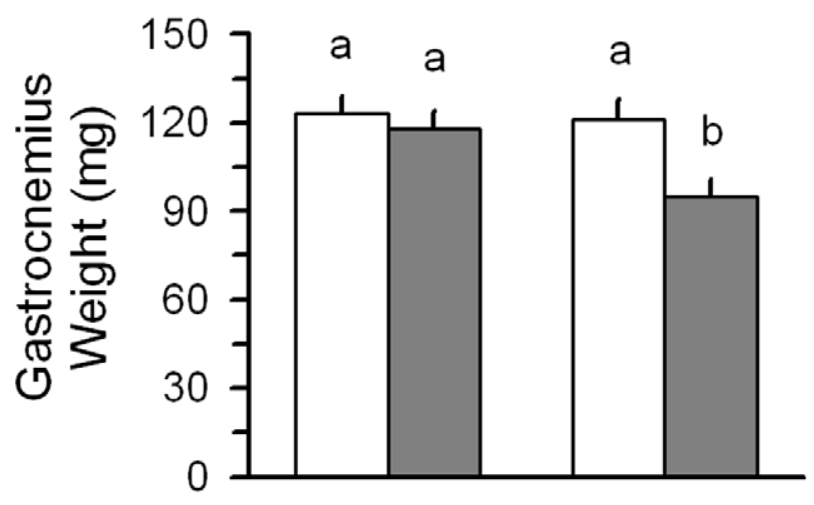

B

$\mathbf{F}$

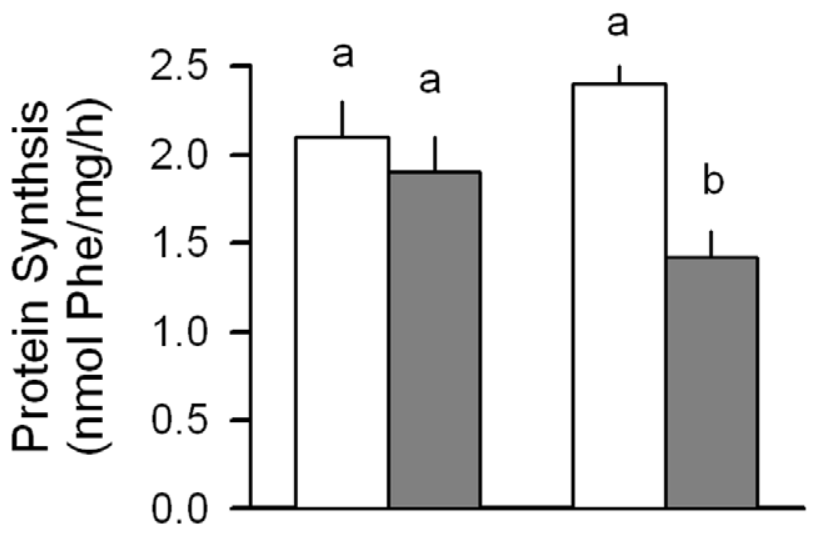

C

\section{P-4E-BP1}

(T37/46)

Total 4E-BP1

P-S6

(S240/244)

Total $\mathrm{S6}$

P-Akt

(S473)

Total Akt

P-PRAS40

(T246)

Total PRAS40

D

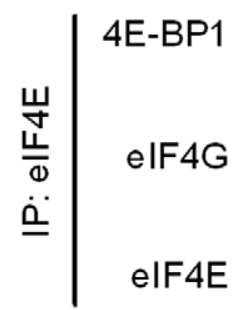

E

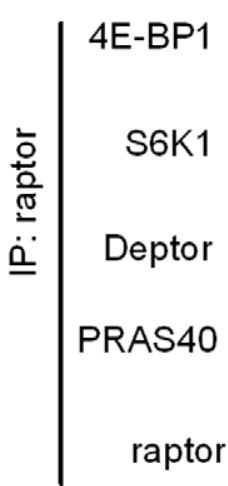

$\frac{\text { Control }}{W T \text { mTOR }^{+/-}} \frac{\text { Immobilized }}{\text { WT } \text { mTOR }^{+/-}}$
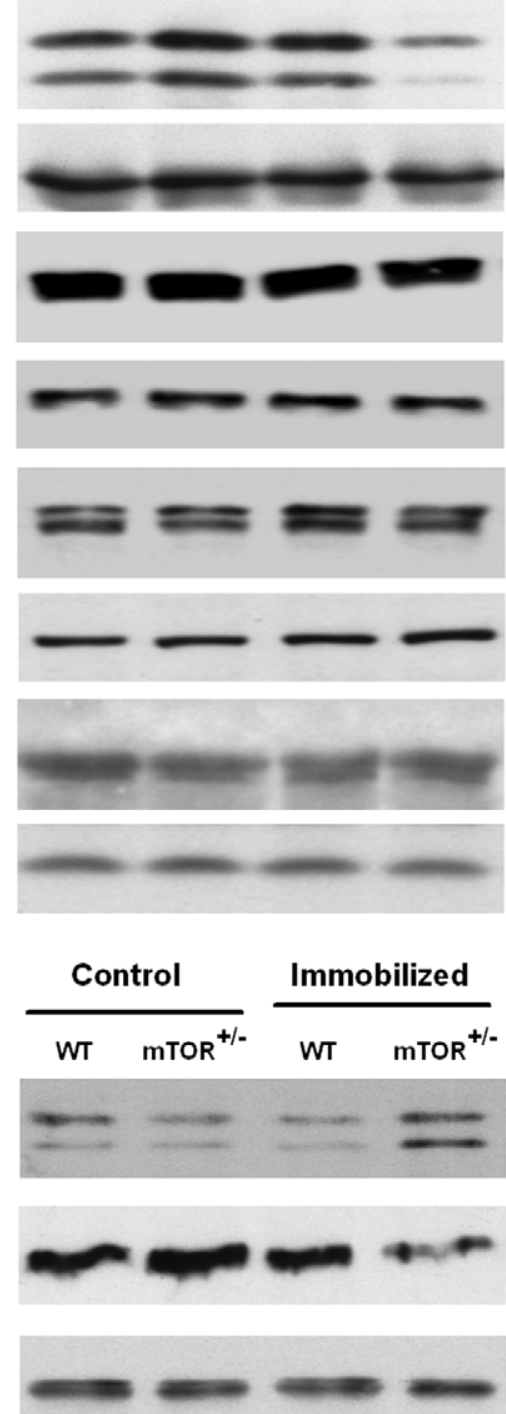
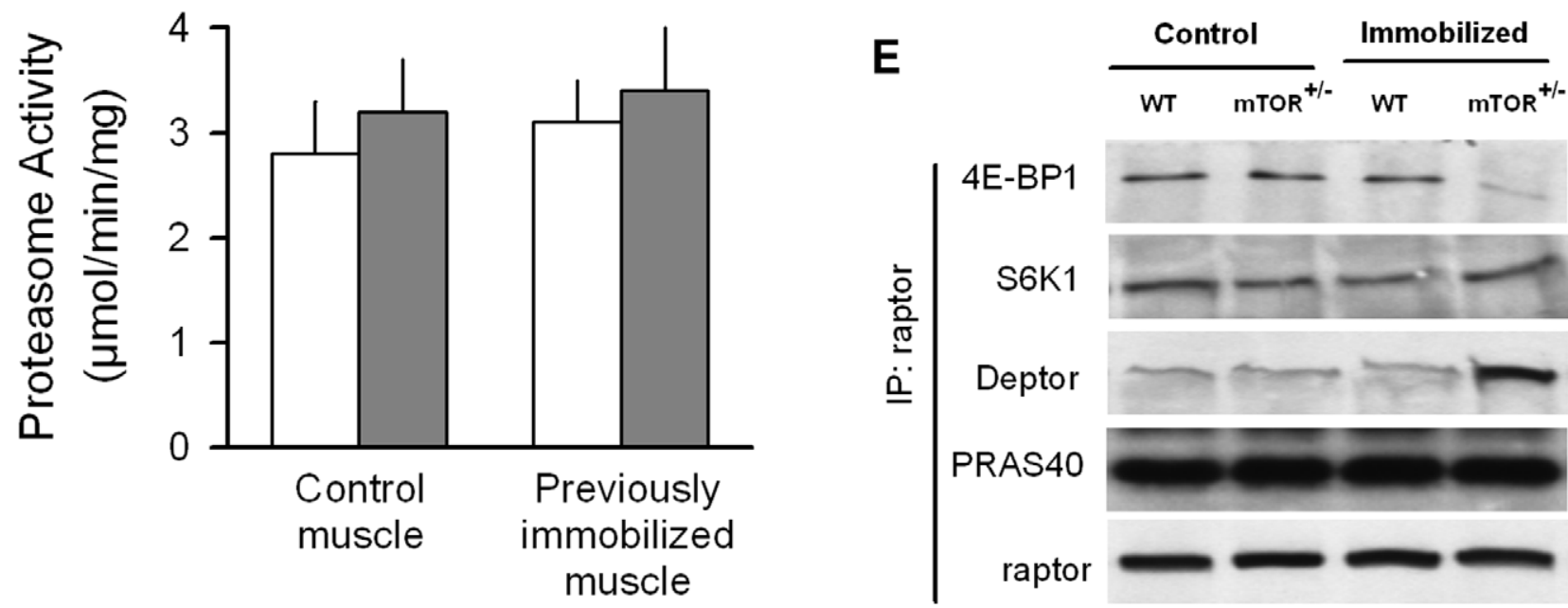
Figure 9. Protein metabolic effects in wild-type (WT) and $\mathrm{mTOR}^{+/-}$mice during recovery from hindlimb immobilization. For all studies, mice had one hindlimb casted for a period of 7 days, the cast removed, and endpoints assessed after 10 days of recovery. (C) Western blot data and are representative of $n=5$ per group. (D) elF4E was immunoprecipitated (IP) from muscle homogenates and immunoblotted for either 4E$\mathrm{BP1}$, elF4G or elF4E, and representative blots are shown. (E) Raptor was immunoprecipitated from muscle homogenates and immunoblotted for either 4E-BP1, S6K1, PRAS40, Deptor or raptor. Data from mice included in this figure are different from that presented in Figure 8. Values with different superscript letters $(a, b)$ are statistically significant $(P<0.05)$. For all bar graphs $(A, B$ and $F)$, values are means \pm SEM; $7-9$ mice per group. doi:10.1371/journal.pone.0038910.g009

from $\mathrm{mTOR}^{+/-}$mice, compared to either the contralateral control muscle or muscle from the control mice. Conversely, the amount of eIF4G bound to eIF4E (e.g., active complex) was decreased in the reloaded muscle of $\mathrm{mTOR}^{+/-}$mice (Figure 9D).

Finally, raptor functions as a scaffold protein recruiting substrates to mTORC1 [38]. Therefore, raptor was immunoprecipitated and then immunoblotted for 4E-BP1, S6K1, PRAS40 and Deptor. The decreased muscle protein synthesis in the previously immobilized muscle at day 10 of the recovery period was associated with a reduction in raptor $4 \mathrm{E}-\mathrm{BP} 1$ binding and an

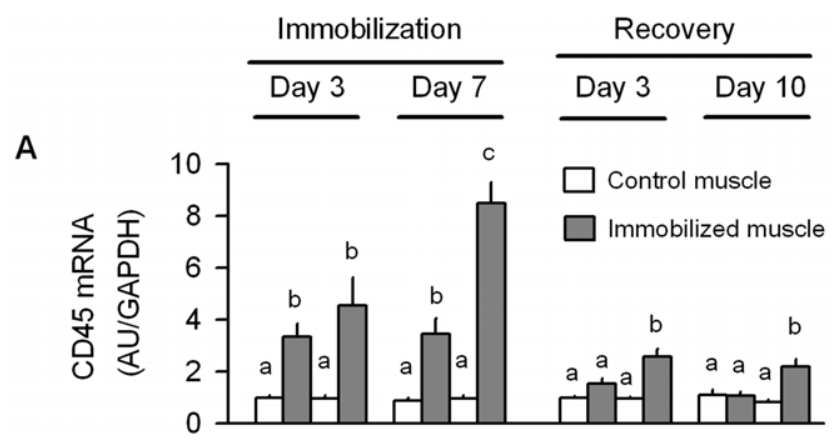

B

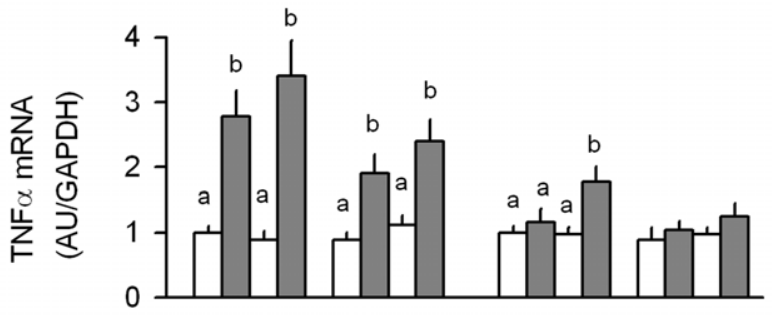

C

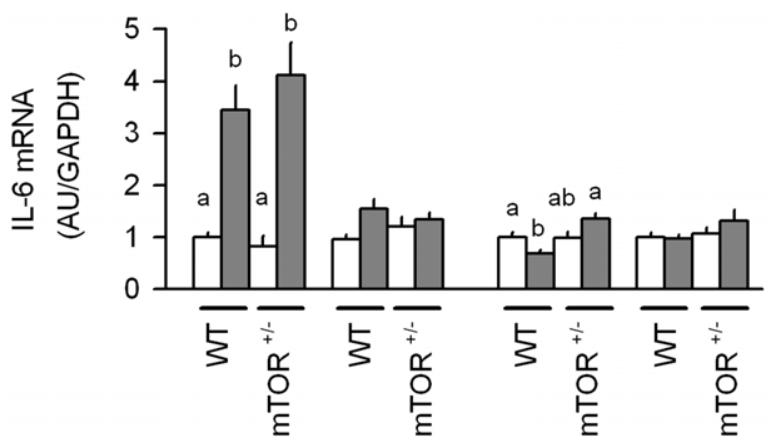

Figure 10. Skeletal muscle mRNA content of inflammatory markers in response to immobilization and recovery in WT and $\mathbf{m T O R}^{+/-}$mice. The relative content of (A) CD45, (B) TNF $\alpha$, and (C) IL6 mRNAs as determined by qRT-PCR on gastrocnemius obtained at either 3 or 7 days of unilateral hindlimb immobilization or at 3 or 10 days after recovery from disuse. Data from the immobilized muscle are compared to that of the contralateral non-casted control muscle in the same mouse. All data were normalized to GAPDH and the WT control value was set at 1.0 arbitrary units (AU/GAPDH). Values with different superscript letters $(a, b, c)$ are statistically significant $(P<0.05)$. For all bar graphs, values are means \pm SEM; 7-9 mice per group. doi:10.1371/journal.pone.0038910.g010 increased amount of raptor $\bullet$ Deptor complex (Figure 9E). In contrast, the binding of raptor with S6K1 and PRAS40 was not altered at this time. As Deptor is also a constituent of mTORC2, we attempted to determine the binding of Deptor to this complex, but we were unable to obtain reliable immunoblots of Deptor from rictor immunoprecipitates (data not shown).

\section{Impact of hindlimb immobilization and reloading on inflammation and IGF-I in WT and mTOR+/- mice}

We also quantified the mRNA content for CD45, a panleukocyte marker, as well as the inflammatory cytokines TNF $\alpha$ and IL-6 which have been implicated in mediating the local inflammatory process and the atrophic response [39-41]. After 3 days of immobilization, both WT and $\mathrm{mTOR}^{+/-}$mice had comparable increases for muscle CD45, TNF $\alpha$ and IL-6 mRNA (Figure 10A-C, respectively). By day 7 of immobilization in WT mice, CD45 and TNF $\alpha$ remained increased, but IL- 6 had returned to values seen in the non-casted contralateral control muscle. A similar response was detected in $\mathrm{mTOR}^{+/-}$mice, except that the immobilization-induced increase in CD45 was greater in the mTOR heterozygous mice than WT animals. The inflammatory state was also profiled during the early (e.g., 3 days) and late (10 days) phase of recovery after cast removal. In WT mice, CD45 and TNF $\alpha$ mRNA did not differ between the previously immobilized and the control muscle after 3 days of recovery; however, IL-6 was reduced by $40 \%$. After 10 days of recovery in WT mice, no immobilization-induced change in local inflammatory markers was detected. For $\mathrm{mTOR}^{+/-}$mice, the increased CD45 and TNF $\alpha$ mRNA seen at day 3 of recovery was greater than in time-matched WT mice, and CD45 was still elevated in $\mathrm{mTOR}^{+/-}$mice after 10 days of reloading.

IGF-I is an endocrine and autocrine regulator of muscle mass [42], its relatively importance as a mediator of atrophy and muscle regrowth in various conditions remains controversial $[43,44]$. An immobilization-induced decrease in IGF-I mRNA was detected by day 7 of immobilization, but not at the 3-day time point, and this temporal response was similar in both $\mathrm{WT}$ and $\mathrm{mTOR}^{+/-}$mice (Figure 11A). An opposite change in IGF-I mRNA was observed in WT mice in response to reloading. That is, the previously immobilized muscle of WT mice exhibited a 4- to 5-fold increase in IGF-I mRNA after 3 days of recovery, compared the noncasted control muscle. IGF-I mRNA was still increased in WT mice after 10 days of recovery. This compensatory increase in IGF-I observed in WT mice during reloading was completely absent in $\mathrm{mTOR}^{+/-}$mice (Figure 11A).

The plasma concentration of IGF-I did not differ between WT and $\mathrm{mTOR}^{+/-}$mice at day 3 or 7 of immobilization or day or 10 of recovery (Figure 11B). Likewise, the plasma insulin concentration did not differ between $\mathrm{WT}$ and $\mathrm{mTOR}^{+/-}$mice at any time point assessed (Figure 11C).

\section{Discussion}

Various animal models have been employed to investigate the metabolic changes produced by muscle disuse. The most widely used of these is likely hindlimb suspension, but an atrophic 

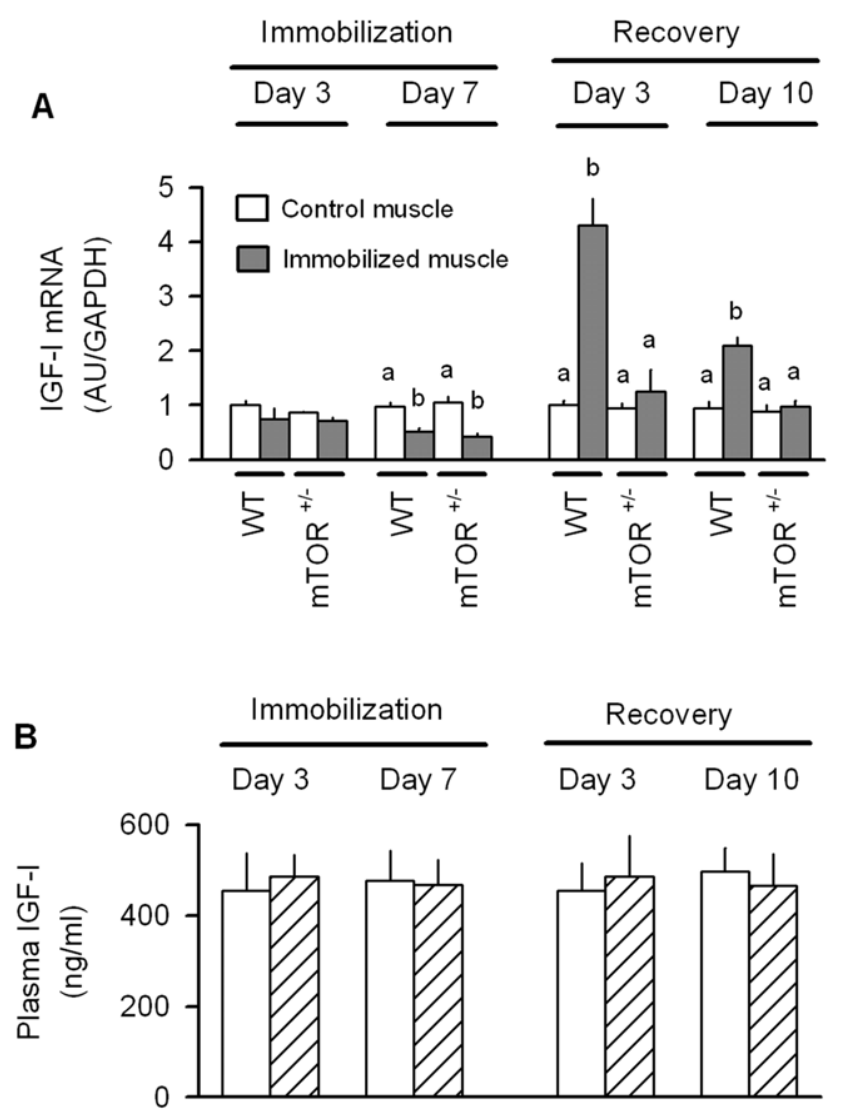

C

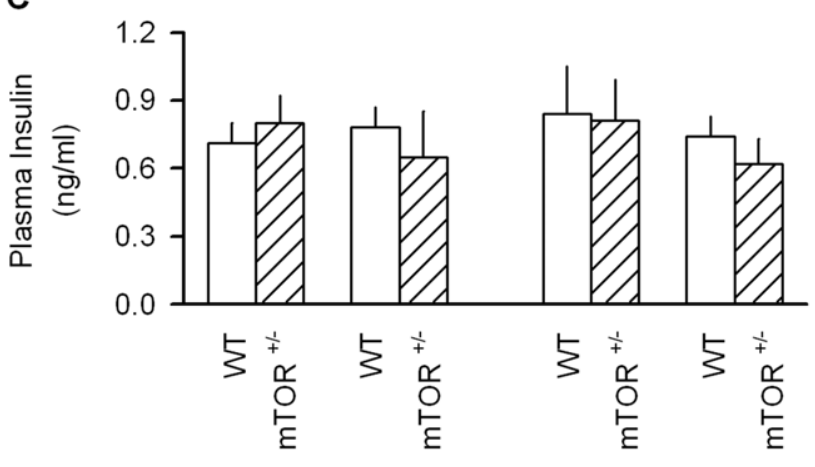

Figure 11. Skeletal muscle mRNA content of IGF-I as well as the plasma concentration of IGF-I and insulin in WT and $\mathrm{mTOR}^{+/-}$ mice during immobilization and recovery. (A) The relative content of IGF-I mRNA determined by qRT-PCR on gastrocnemius obtained at either 3 or 7 days of unilateral hindlimb immobilization or at 3 or 10 days after recovery from disuse. The primer probe used recognizes all IGF-I transcripts [80]. Data from the immobilized muscle are compared to that of the contralateral non-casted control muscle in the same mouse. All data were normalized to GAPDH and the WT control value was set at 1.0 arbitrary units (AU/GAPDH). Values with different superscript letters $(a, b, c)$ are statistically significant $(P<0.05)$. $(B, C)$ The plasma concentrations for IGF-I and insulin, respectively, did not different between WT and $\mathrm{mTOR}^{+/-}$mice at the time points assessed. For all bar graphs, values are means \pm SEM; 7-9 mice per group.

doi:10.1371/journal.pone.0038910.g011

response is seen in response to extended bed rest, denervation, or hindlimb immobilization (either bilateral or unilateral). Each model has specific strengths which encourage its use as well as weaknesses which limit data interpretation [45]. Although other murine models of immobilization have been reported [46,47], the current series of experiments were performed using a newly developed unilateral hindlimb immobilization model which is easy to implement and requires no specialized equipment, permits comparison of the immobilized to control muscle in the same mouse, maintains neural innervation to the musculature, does not alter food consumption, permits recovery-type studies to be performed, and produces a relatively low level of animal stress. As we are aware of no investigation which reports the temporal progression of changes in both muscle protein synthesis and degradation during both a period of immobilization and recovery in the same animal model, our initial studies focused on the metabolic characterization of this new murine model.

The immobilized hindlimb demonstrated progressive atrophy of the gastrocnemius during the 7 day experimental protocol. It is noteworthy that this localized muscle atrophy did not decrease whole-body lean mass, as assessed by ${ }^{1} \mathrm{H}-\mathrm{NMR}$, and this consistent with the unaltered food consumption in casted mice. Disuse atrophy results from an imbalance between rates of protein synthesis and degradation. The consensus from the available literature indicates a reduction in muscle protein synthesis, which commences as early as $6 \mathrm{~h}$ after immobilization [1 1$]$ and remains decreased for several days to weeks $[5,48]$. Several previous studies of muscle disuse have revealed a close association between reduced protein synthesis and impaired mTORG1 activity, as evidenced by the coordinate decrease in phosphorylated S6K1 (or S6) and 4EBP1 [6,19-21], and our current data are consistent with the these previous reports. Additionally, we also detected an immobilization-induced decrease in S473-phosphorylated Akt, similar to that previously reported [18], suggesting either a direct or indirect inhibition of mTORC2 activity. Moreover, immobilization impaired the ability of leucine to acutely stimulate muscle protein synthesis and 4E-BP1 phosphorylation. Such data are consistent with the anabolic resistance seen in human muscle after 14 days of immobilization [14]. Despite the recognized importance of mTOR signaling in regulating protein balance, our data indicate that the immobilization-induced decrement in muscle mass and protein synthesis was comparable in $\mathrm{WT}$ and $\mathrm{mTOR}^{+/-}$mice. These data are consistent with the previous work of Bodine et al [18] where in vivo administration of the mTOR inhibitor rapamycin did not alter muscle weight in mature rodents, suggesting that maintenance of muscle weight under basal control conditions is not mTOR-dependent.

The atrophic response to muscle disuse is also partially mediated by increased protein degradation. Although the relative importance of the various proteolytic pathways is still a area of controversy and may appear to be dependent upon the etiology of the atrophic insult [46], however, a diverse array of catabolic conditions activate the ubiquitin proteasome pathway [22,33]. Muscle disuse increases the mRNA content for the muscle-specific ubiquitin E3 ligases atrogin-1 and MuRF1 [6,8,21,47,49,50], whereas knock down of these atrogenes ameliorates the loss of muscle mass induced by denervation or hindlimb suspension [10,51]. Collectively, atrogin-1 and MuRF1 mRNA expression is routinely used as a surrogate marker for muscle proteolysis. However, while the immobilization-induced up-regulation of atrogenes is commonly detected, the duration of the increase is variable and often transient $[8,47,50,52]$. In the current study, we found both atrogin-1 and MuRF1 mRNA had returned to levels seen in the control muscle by day 7 of immobilization. However, proteasome activity was still elevated in the immobilized muscle at this specific time point. The discordant association of proteasome activity and atrogene expression may suggest atrogin-1 and/or MuRF1 do not catalyze the rate controlling step in protein 
degradation. In this regard, cleavage of sarcomeric proteins by calpain may be necessary to provide substrate for the ubiquitin proteasome system [53]. Therefore, it is possible that proteasome activity can be increased without a concomitant elevation in either atrogin-1 or MuRF1. Alternatively, there may be a discordant regulation of atrogene mRNA and protein expression, which was not assessed in the current study because of the relatively limited mass of available muscle. The lysosomal-autophagy pathway also contributes to protein degradation in selected models of muscle atrophy [54]. However, while autophagy-related genes are upregulated in response to differing atrophic stimuli [54,55], other studies have reported that such an increase is not evident in immobilized muscle [46]. Finally, the current study did not investigate changes in muscle apoptosis which has been shown to be increased in immobilized muscle [13,39]. Hence, the relative contribution of autophagy and apoptosis to immobilizationinduced in this particular model of disuse remains to be elucidated. Similar to protein synthesis, all measured indices of protein degradation in the immobilized muscle did not differ between WT and $\mathrm{mTOR}^{+/-}$mice during the immobilization phase.

In many chronic catabolic states, elevated blood borne proinflammatory cytokines induce muscle wasting by decreasing protein synthesis and/or increasing protein degradation $[53,56]$. Furthermore, myocytes contribute to the innate immune response by synthesizing and secreting a host of proinflammatory cytokines [57], and the local activation of nuclear factor-kappa $B$ is sufficient to produced muscle atrophy [58-60]. In this regard, the consistent elevation in CD45 mRNA throughout immobilization suggests a marked infiltration of inflammatory leukocytes. Moreover, the sustained increase in TNF $\alpha \mathrm{mRNA}$ and the more transient increase in IL-6, is indicative of a localized muscle inflammation. While we were unable to resolve the temporal progression of infiltrating leukocytes versus cytokine synthesis in our current study, previous work has reported that an in increase in TNF $\alpha$, IL1 and IL-6 precede the immobilization-induced increase in CD45 [47]. Based on the sustained increase in TNF $\alpha$ in the immobilized muscle, coupled with the changes in both protein synthesis and proteolysis, we cannot exclude this cytokine as a potential mediator of the atrophic response. The role of mTOR in regulating the innate immune response in leukocytes is poorly defined and may vary depending on whether pro- or antiinflammatory cytokine production is being examined [61]. In the current study, there was no difference in the immobilizationinduced increase in TNF $\alpha$ or IL- 6 between $\mathrm{WT}$ and $\mathrm{mTOR}^{+/-}$ mice. However, mTOR haploinsufficient mice did exhibit an exaggerated increase in CD45 mRNA on day 7 of immobilization, but the cause and physiological importance of this difference remains unclear.

Although $\mathrm{TNF} \alpha$ or an unidentified cytokine may directly mediate the atrophic response during the unloading phase, these immunomodulators may also function in an indirect manner by reducing the local concentration of an anabolic mediator. One such potent mitogen is IGF-I which functions both as a traditional endocrine hormone, but also by an autocrine/paracrine mechanism [42,62]. In this regard, exogenously delivered IGF-I ameliorates wasting produced by excess glucocorticoids [63], denervation [64], and sepsis [65], and the local over-expression of a muscle-restricted IGF-I isoform can prevent decrement in muscle loss seen with aging [66] and neuromuscular disease [67]. In contrast, others have reported that the localized over-expression of IGF-I in muscle does not prevent the casting-induced decrease in muscle mass and force generation $[16,68]$. Our data and others [16] show a marked reduction in muscle IGF-I mRNA in immobilized muscle. However, the temporal progression of the immobilization-induced change in IGF-I was not consistent with the accompanying alterations in protein synthesis or atrogene expression. While these data suggest the decreased muscle IGF-I is an unlikely mediator of disuse atrophy, our data should be interpreted cautiously as we assayed all muscle IGF-I transcripts. We did not quantify various splice variants or muscle-specific isoforms of IGF-I which may be differentially regulated and which may have differing bioactivities [69], but whose physiological functions remain controversial [70].

It is important to distinguish between mechanisms responsible for disuse atrophy and those which promote muscle repair upon reloading as they likely differ [71]. Therefore, using the same murine model we also examined the role of mTOR in the recovery of muscle mass. In WT mice protein synthesis is selectively elevated in the previously immobilized muscle within $24 \mathrm{~h}$ of reloading and the increase persists for at least 6 days. By day 10 of recovery, both protein synthesis and muscle weight had returned to control values in WT mice. However, despite the normalization of muscle protein synthesis by 10 days of recovery, the previously immobilized muscle still exhibited leucine resistance. Characterization of metabolic changes in both the atrophy and recovery phase is important, as the temporal progression of muscle regrowth appears to be inversely proportional to the duration of immobilization [3,7,27,28,45,72]. Moreover, the ability of mice to fully recover muscle mass is in contrast to the more prolonged time for muscle repair and regeneration needed in rats [13,27,73].

In contrast to WT mice, there was a significant delay in the reloading-induced accretion of muscle protein in previously immobilized muscle from $\mathrm{mTOR}^{+/-}$mice. The impaired response was caused by a reduced rate of muscle protein synthesis, with no apparent difference in the rate of degradation (e.g., proteasome activity). The decreased rate of protein synthesis in reloaded muscle from $\mathrm{mTOR}^{+/-}$mice was associated with a reduction in phosphorylation of $4 \mathrm{E}-\mathrm{BP} 1$, but not $\mathrm{S} 6$. The reason for this divergent mTOR signaling response is not understood, but emphasizes the need to determine both the activation of specific signal transduction pathways as well as protein synthesis per se.

mTORC1 is a multiprotein complex with raptor functioning as a scaffold protein recruiting a variety of substrates [17]. Raptor binds to the TOR signaling motif found in all known substrates of mTORC1, including 4E-BP1, S6K1 and PRAS40 [74]. In the previously immobilized muscle from $\mathrm{mTOR}^{+/-}$mice which exhibited delay regrowth, the binding of $4 \mathrm{E}-\mathrm{BP} 1$ to raptor was decreased. This observation is consistent with the endotoxininduced decrease in muscle protein synthesis and mTORC1 activity previously reported [75] and, conversely, the recruitment of $4 \mathrm{E}-\mathrm{BP} 1$ to raptor for optimal stimulation of protein synthesis [76]. However, this defect appeared to be relatively selective and was not a generalized phenomenon as the binding of raptor to either S6K1 or PRAS40 was not altered. However, Deptor is a negative-regulator of mTOR kinase activity in skeletal muscle [12] and the interaction of Deptor with raptor was increased in the previously immobilized muscle from $\mathrm{mTOR}^{+/-}$mice. Finally, in contrast to the inhibition of mTORG1 signaling, S473-phosphorylated Akt and T246- phosphorylated PRAS40 did not differ from values from the contralateral control muscle.

The protein metabolic changes in WT mice were temporally associated with an increase in IGF-I mRNA, and the impaired ability of $\mathrm{mTOR}^{+/-}$mice to replete mass was associated with a failure of these animals to increase IGF-I in a compensatory manner. Although somewhat counterintuitive, the up-regulation of the local inflammatory response in muscle is also necessary for efficient muscle recovery from disuse $[77,78]$. We did not see a reloading-induced increase in muscle CD45, TNF $\alpha$ or IL-6 in WT 
mice in the current study and this may be explained by a relatively transient cytokine response which we missed by only sampling tissue at day 3 and 10 of recovery. In contrast, $\mathrm{mTOR}^{+/-}$mice showed a relatively small but sustained increase in CD45 throughout the duration of the 10-day recovery period which was associated with a transient early (day 3) increase in $\mathrm{TNF} \alpha$ and IL-6. However, we speculate that the limited difference in the magnitude of the inflammatory response between $\mathrm{mTOR}^{+/-}$and WT mice, is an unlikely mediator for the differences in protein balance and mass during the recovery period. In general, our data are consistent with previous reports concluding that recovery is associated with an increase in the phosphorylation-activation state of various elements of the IGF-I/AKT/mTOR pathway $[18,20,79]$ and that locally delivered IGF-I can enhance muscle regeneration during the recovery period [16].

In summary, our data indicate that muscle loss is mediated by rapid and sustained changes in both protein synthesis and degradation which cannot be attributed to a localized change in IGF-I. While these disuse-induced changes are likely mediated through inhibition of the canonical mTOR signaling pathway, a reduction in the total amount of $\operatorname{mTOR}$ (as seen in the $\mathrm{mTOR}^{+/-}$

\section{References}

1. Frost RA, Lang CH (2007) Protein kinase B/Akt: a nexus of growth factor and cytokine signaling in determining muscle mass. J Appl Physiol 103: 378-387.

2. Hood DA, Irrcher I, Ljubicic V, Joseph AM (2006) Coordination of metabolic plasticity in skeletal muscle. J Exp Biol 209: 2265-2275.

3. Evans WJ (2010) Skeletal muscle loss: cachexia, sarcopenia, and inactivity. Am J Clin Nutr 91: 1123S-1127S

4. Fitts RH, Romatowski JG, Peters JR, Paddon-Jones D, Wolfe RR, et al. (2007) The deleterious effects of bed rest on human skeletal muscle fibers are exacerbated by hypercortisolemia and ameliorated by dietary supplementation. Am J Physiol Cell Physiol 293: C313-C320.

5. Gibson JN, Halliday D, Morrison WL, Stoward PJ, Hornsby GA, et al. (1987) Decrease in human quadriceps muscle protein turnover consequent upon leg immobilization. Clin Sci (Lond) 72: 503-509.

6. Gustafsson T, Osterlund T, Flanagan JN, von Waldén, Trappe TA, et al. (2010) Effects of 3 days unloading on molecular regulators of muscle size in humans. J Appl Physiol 109: 721-727.

7. Kim SJ, Roy RR, Zhong H, Suzuki H, Ambartsumyan L, et al. (2007) Electromechanical stimulation ameliorates inactivity-induced adaptations in the medial gastrocnemius of adult rats. J Appl Physiol 103: 195-205.

8. Krawiec BJ, Frost RA, Vary TC, Jefferson LS, Lang CH (2005) Hindlimb casting decreases muscle mass in part by proteasome-dependent proteolysis but independent of protein synthesis. Am J Physiol Endocrinol Metab 289: E969E980.

9. LeMoine JK, Haus JM, Trappe SW, Trappe TA (2009) Muscle proteins during 60-day bedrest in women: impact of exercise or nutrition. Muscle Nerve 39: $463-471$.

10. Bodine SC, Latres E, Baumhueter S, Lai VK, Nunez L, et al. (2001) Identification of ubiquitin ligases required for skeletal muscle atrophy. Science 294: 1704-1708.

11. Booth FW, Seider MJ (1979) Early change in skeletal muscle protein synthesis after limb immobilization of rats. J Appl Physiol 47: 974-977.

12. Kazi AA, Hong-Brown L, Lang SM, Lang CH (2011) Deptor knockdown enhances mTOR Activity and protein synthesis in myocytes and ameliorates disuse muscle atrophy. Mol Med 17: 925-936.

13. Vazeille E, Codran A, Claustre A, Averous J, Listrat A, et al. (2008) The ubiquitin-proteasome and the mitochondria-associated apoptotic pathways are sequentially downregulated during recovery after immobilization-induced muscle atrophy. Am J Physiol Endocrinol Metab 295: E1181-E1190.

14. Glover EI, Phillips SM, Oates BR, Tang JE, Tarnopolsky MA, et al. (2008) Immobilization induces anabolic resistance in human myofibrillar protein synthesis with low and high dose amino acid infusion. J Physiol 586: 6049-6061.

15. Stelzer JE, Widrick JJ (2003) Effect of hindlimb suspension on the functional properties of slow and fast soleus fibers from three strains of mice. J Appl Physiol 95: 2425-2433.

16. Stevens-Lapsley JE, Ye F, Liu M, Borst SE, Conover C, et al. (2010) Impact of viral-mediated IGF-I gene transfer on skeletal muscle following cast immobilization. Am J Physiol Endocrinol Metab 299: E730-E740.

17. Frost RA, Lang CH (2011) mTor signaling in skeletal muscle during sepsis and inflammation: where does it all go wrong? Physiology (Bethesda ) 26: 83-96.

18. Bodine SC, Stitt TN, Gonzalez M, Kline WO, Stover GL, et al. (2001) Akt/ mTOR pathway is a crucial regulator of skeletal muscle hypertrophy and can prevent muscle atrophy in vivo. Nat Cell Biol 3: 1014-1019. mice) in muscle does not exacerbate the metabolic imbalance in the immobilized muscle. However, the ability of mTOR heterozygous mice to increase protein synthesis in response to the anabolic signals generated by reloading was greatly impaired. These data support the contention that the inability to fully activate mTOR in previously immobilized muscle limits muscle regrowth and suggests stimulation of this kinase might be expected to preferentially enhance regrowth, but with little salutary effect on the initial loss of muscle.

\section{Acknowledgments}

The authors gratefully acknowledge the expert technical assistance of Anne Pruznak, Margaret Shumate, Maithili Navaratnarajah and Gina Deiter.

\section{Author Contributions}

Conceived and designed the experiments: SL AK LH CL. Performed the experiments: SL AK CL. Analyzed the data: SL AK LH CL. Contributed reagents/materials/analysis tools: SL AK LH CL. Wrote the paper: SL AK LH CL.

19. Burks TN, Andres-Mateos E, Marx R, Mejias R, Van EC, et al. (2011) Losartan restores skeletal muscle remodeling and protects against disuse atrophy in sarcopenia. Sci Transl Med 3: 82ra37.

20. Childs TE, Spangenburg EE, Vyas DR, Booth FW (2003) Temporal alterations in protein signaling cascades during recovery from muscle atrophy. Am J Physiol Cell Physiol 285: C391-C398.

21. Haddad F, Roy RR, Zhong H, Edgerton VR, Baldwin KM (2003) Atrophy responses to muscle inactivity. II. Molecular markers of protein deficits. J Appl Physiol 95: 791-802.

22. Murton AJ, Constantin D, Greenhaff PL (2008) The involvement of the ubiquitin proteasome system in human skeletal muscle remodelling and atrophy. Biochim Biophys Acta 1782: 730-743.

23. Risson V, Mazelin L, Roceri M, Sanchez H, Moncollin V, et al. (2009) Muscle inactivation of mTOR causes metabolic and dystrophin defects leading to severe myopathy. J Cell Biol 187: 859-874.

24. Gangloff YG, Mueller M, Dann SG, Svoboda P, Sticker M, et al. (2004) Disruption of the mouse mTOR gene leads to early postimplantation lethality and prohibits embryonic stem cell development. Mol Cell Biol 24: 9508-9516.

25. Murakami M, Ichisaka T, Maeda M, Oshiro N, Hara K, et al. (2004) mTOR is essential for growth and proliferation in early mouse embryos and embryonic stem cells. Mol Cell Biol 24: 6710-6718.

26. Lang CH, Frost RA, Bronson SK, Lynch CJ, Vary TC (2010) Skeletal muscle protein balance in mTOR heterozygous mice in response to inflammation and leucine. Am J Physiol Endocrinol Metab 298: E1283-E1294.

27. Magne H, Savary-Auzeloux I, Vazeille E, Claustre A, Attaix D, et al. (2011) Lack of muscle recovery after immobilization in old rats does not result from a defect in normalization of the ubiquitin-proteasome and the caspase-dependent apoptotic pathways. J Physiol 589: 511-524.

28. Vargas R, Lang CH (2008) Alcohol accelerates loss of muscle and impairs recovery of muscle mass resulting from disuse atrophy. Alcohol Clin Exp Res 32: $128-137$.

29. Vary TC, Lang CH (2008) Assessing effects of alcohol consumption on protein synthesis in striated muscles. Methods Mol Biol 447: 343-355.

30. Lang CH, Frost RA, Nairn AC, MacLean DA, Vary TC (2002) TNF-alpha impairs heart and skeletal muscle protein synthesis by altering translation initiation. Am J Physiol Endocrinol Metab 282: E336-E347.

31. Garlick PJ, McNurlan MA, Essen P, Wernerman J (1994) Measurement of tissue protein synthesis rates in vivo: a critical analysis of contrasting methods. Am J Physiol 266: E287-E297.

32. Livak KJ, Schmittgen TD (2001) Analysis of relative gene expression data using real-time quantitative PCR and the 2(-Delta Delta C(T)) Method. Methods 25: $402-408$.

33. Foletta VC, White LJ, Larsen AE, Leger B, Russell AP (2011) The role and regulation of MAFbx/atrogin-1 and MuRF1 in skeletal muscle atrophy. Pflugers Arch 461: 325-335.

34. Frost RA, Nystrom GJ, Jefferson LS, Lang CH (2007) Hormone, cytokine, and nutritional regulation of sepsis-induced increases in atrogin-1 and MuRF1 in skeletal muscle. Am J Physiol Endocrinol Metab 292: E501-E512.

35. Gomes MD, Lecker SH, Jagoe RT, Navon A, Goldberg AL (2001) Atrogin-1, a muscle-specific F-box protein highly expressed during muscle atrophy. Proc Natl Acad Sci U S A 98: 14440-14445. 
36. Vary TC, Frost RA, Lang CH (2008) Acute alcohol intoxication increases atrogin-1 and MuRF1 mRNA without increasing proteolysis in skeletal muscle. Am J Physiol Regul Integr Comp Physiol 294: R1777-R1789.

37. Yu Y, Yoon SO, Poulogiannis G, Yang Q Ma XM, et al. (2011) Phosphoproteomic analysis identifies Grb10 as an mTORC1 substrate that negatively regulates insulin signaling. Science 332: 1322-1326.

38. Kim DH, Sarbassov DD, Ali SM, King JE, Latek RR, et al. (2002) mTOR interacts with raptor to form a nutrient-sensitive complex that signals to the cell growth machinery. Cell 110: 163-175.

39. Dogra G, Changotra H, Wedhas N, Qin X, Wergedal JE, et al. (2007) TNFrelated weak inducer of apoptosis (TWEAK) is a potent skeletal muscle-wasting cytokine. FASEB J 21: 1857-1869.

40. Li H, Malhotra S, Kumar A (2008) Nuclear factor-kappa B signaling in skeletal muscle atrophy. J Mol Med (Berl) 86: 1113-1126.

41. Peterson JM, Feeback KD, Baas JH, Pizza FX (2006) Tumor necrosis factoralpha promotes the accumulation of neutrophils and macrophages in skeletal muscle. J Appl Physiol 101: 1394-1399.

42. Frost RA, Lang CH (2003) Regulation of insulin-like growth factor-I in skeletal muscle and muscle cells. Minerva Endocrinol 28: 53-73.

43. Flueck M, Goldspink G (2010) Point:Counterpoint: IGF is/is not the major physiological regulator of muscle mass. Counterpoint: IGF is not the major physiological regulator of muscle mass. J Appl Physiol 108: 1821-1823.

44. Stewart CE, Pell JM (2010) Point:Counterpoint: IGF is/is not the major physiological regulator of muscle mass. Point: IGF is the major physiological regulator of muscle mass. J Appl Physiol 108: 1820-1821.

45. Machida S, Booth FW (2004) Regrowth of skeletal muscle atrophied from inactivity. Med Sci Sports Exerc 36: 52-59.

46. Bialek P, Morris C, Parkington J, St Andre M, Owens J, et al. (2011) Distinct protein degradation profiles are induced by different disuse models of skeletal muscle atrophy. Physiol Genomics 43: 1075-1086.

47. Caron AZ, Drouin G, Desrosiers J, Trensz F, Grenier G (2009) A novel hindlimb immobilization procedure for studying skeletal muscle atrophy and recovery in mouse. J Appl Physiol 106: 2049-2059.

48. Tucker KR, Seider MJ, Booth FW (1981) Protein synthesis rates in atrophied gastrocnemius muscles after limb immobilization. J Appl Physiol 51: 73-77.

49. Bajotto G, Sato Y, Kitaura Y, Shimomura Y (2011) Effect of branched-chain amino acid supplementation during unloading on regulatory components of protein synthesis in atrophied soleus muscles. Eur J Appl Physiol 111: 18151828.

50. Murphy KT, Cobani V, Ryall JG, Ibebunjo C, Lynch GS (2011) Acute antibody-directed myostatin inhibition attenuates disuse muscle atrophy and weakness in mice. J Appl Physiol 110: 1065-1072.

51. Labeit S, Kohl CH, Witt CC, Labeit D, Jung J, et al. (2010) Modulation of muscle atrophy, fatigue and MLC phosphorylation by MuRF1 as indicated by hindlimb suspension studies on MuRF1-KO mice. J Biomed Biotechnol 2010: 693741.

52. Abadi A, Glover EI, Isfort RJ, Raha S, Safdar A, et al. (2009) Limb immobilization induces a coordinate down-regulation of mitochondrial and other metabolic pathways in men and women. PLoS One 4: e6518.

53. Smith IJ, Lecker SH, Hasselgren PO (2008) Calpain activity and muscle wasting in sepsis. Am J Physiol Endocrinol Metab 295: E762-E771.

54. Zhao J, Brault JJ, Schild A, Cao P, Sandri M, et al. (2007) FoxO3 coordinately activates protein degradation by the autophagic/lysosomal and proteasomal pathways in atrophying muscle cells. Cell Metab 6: 472-483.

55. Yamamoto D, Maki T, Herningtyas EH, Ikeshita N, Shibahara H, et al. (2010) Branched-chain amino acids protect against dexamethasone-induced soleus muscle atrophy in rats. Muscle Nerve 41: 819-827.

56. Lang CH, Frost RA, Vary TC (2007) Regulation of muscle protein synthesis during sepsis and inflammation. Am J Physiol Endocrinol Metab 293: E453E459.

57. Frost RA, Lang CH (2005) Skeletal muscle cytokines: regulation by pathogenassociated molecules and catabolic hormones. Curr Opin Clin Nutr Metab Care 8: 255-263.

58. Cai D, Frantz JD, Tawa NE, Melendez PA, Oh BC, et al. (2004) IKKbeta/NFkappaB activation causes severe muscle wasting in mice. Cell 119: 285-298.
59. Mittal A, Bhatnagar S, Kumar A, Lach-Trifilieff E, Wauters S, et al. (2010) The TWEAK-Fn14 system is a critical regulator of denervation-induced skeletal muscle atrophy in mice. J Cell Biol 188: 833-849.

60. Paul PK, Gupta SK, Bhatnagar S, Panguluri SK, Darnay BG, et al. (2010) Targeted ablation of TRAF6 inhibits skeletal muscle wasting in mice. J Cell Biol 191: 1395-1411.

61. Weichhart T, Saemann MD (2008) The PI3K/Akt/mTOR pathway in innate immune cells: emerging therapeutic applications. Ann Rheum Dis 67 Suppl 3: iii70-iii74.

62. Goldspink G (2005) Mechanical signals, IGF-I gene splicing, and muscle adaptation. Physiology (Bethesda) 20: 232-238.

63. Schakman O, Gilson H, de Coninck V, Lause P, Verniers J, et al. (2005) Insulinlike growth factor-I gene transfer by electroporation prevents skeletal muscle atrophy in glucocorticoid-treated rats. Endocrinology 146: 1789-1797.

64. Rabinovsky ED, Gelir E, Gelir S, Lui H, Kattash M, et al. (2003) Targeted expression of IGF-1 transgene to skeletal muscle accelerates muscle and motor neuron regeneration. FASEB J 17: 53-55.

65. Nystrom G, Pruznak A, Huber D, Frost RA, Lang CH (2009) Local insulin-like growth factor I prevents sepsis-induced muscle atrophy. Metabolism 58: 787797.

66. Musaro A, McCullagh K, Paul A, Houghton L, Dobrowolny G, et al. (2001) Localized Igf-1 transgene expression sustains hypertrophy and regeneration in senescent skeletal muscle. Nat Genet 27: 195-200.

67. Dobrowolny G, Giacinti G, Pelosi L, Nicoletti C, Winn N, et al. (2005) Muscle expression of a local Igf-1 isoform protects motor neurons in an ALS mouse model. J Cell Biol 168: 193-199.

68. Criswell DS, Booth FW, DeMayo F, Schwartz RJ, Gordon SE, et al. (1998) Overexpression of IGF-I in skeletal muscle of transgenic mice does not prevent unloading-induced atrophy. Am J Physiol 275: E373-E379.

69. Barton ER (2006) The ABCs of IGF-I isoforms: impact on muscle hypertrophy and implications for repair. Appl Physiol Nutr Metab 31: 791-797.

70. Matheny RW, Nindl BC, Adamo ML (2010) Minireview: Mechano-growth factor: a putative product of IGF-I gene expression involved in tissue repair and regeneration. Endocrinology 151: 865-875.

71. Tidball JG (2005) Inflammatory processes in muscle injury and repair. Am J Physiol Regul Integr Comp Physiol 288: R345-R353.

72. Morris RT, Spangenburg EE, Booth FW (2004) Responsiveness of cell signaling pathways during the failed 15-day regrowth of aged skeletal muscle. J Appl Physiol 96: 398-404.

73. Booth FW (1978) Regrowth of atrophied skeletal muscle in adult rats after ending immobilization. J Appl Physiol 44: 225-230.

74. Nojima H, Tokunaga C, Eguchi S, Oshiro N, Hidayat S, et al. (2003) The mammalian target of rapamycin (mTOR) partner, raptor, binds the mTOR substrates p70 S6 kinase and 4E-BP1 through their TOR signaling (TOS) motif. J Biol Chem 278: 15461-15464.

75. Lang CH, Lynch CJ, Vary TG (2010) BCATm deficiency ameliorates endotoxin-induced decrease in muscle protein synthesis and improves survival in septic mice. Am J Physiol Regul Integr Comp Physiol 299: R935-R944.

76. Holz MK, Ballif BA, Gygi SP, Blenis J (2005) mTOR and S6K1 mediate assembly of the translation preinitiation complex through dynamic protein interchange and ordered phosphorylation events. Cell 123: 569-580.

77. Bondesen BA, Mills ST, Pavlath GK (2006) The COX-2 pathway regulates growth of atrophied muscle via multiple mechanisms. Am J Physiol Cell Physiol 290: C1651-C1659.

78. Washington TA, White JP, Davis JM, Wilson LB, Lowe LL, et al. (2011) Skeletal muscle mass recovery from atrophy in IL-6 knockout mice. Acta Physiol (Oxf) 202: 657-669.

79. Sugiura T, Abe N, Nagano M, Goto K, Sakuma K, et al. (2005) Changes in $\mathrm{PKB} / \mathrm{Akt}$ and calcineurin signaling during recovery in atrophied soleus muscle induced by unloading. Am J Physiol Regul Integr Comp Physiol 288: R1273R1278.

80. Temmerman L, Slonimsky E, Rosenthal N (2010) Class 2 IGF-1 isoforms are dispensable for viability, growth and maintenance of IGF-1 serum levels. Growth Horm IGF Res 20: 255-263. 